\title{
Tirosin Kinase Inhibitors in Chronic Graft versus Host Disease: From Bench to Bedside
}

\author{
Jacopo Olivieri, ${ }^{1}$ Sabrina Coluzzi, ${ }^{2}$ Imma Attolico, ${ }^{2}$ and Attilio Olivieri ${ }^{3}$ \\ ${ }^{1}$ Department of Internal Medicine, Università Politecnica delle Marche, \\ 60121 Ancona, Italy \\ ${ }^{2}$ Department of Hematology, Azienda Ospedaliera San Carlo, 85100 Potenza, Italy \\ ${ }^{3}$ Department of Hematology, Università Politecnica delle Marche, 60121 Ancona, Italy
}

Received 9 August 2011; Accepted 5 September 2011

Academic Editor: Edward Benz

Chronic Graft Versus Host Disease (cGVHD) is a major complication of allogeneic stem-cell transplantation (SCT). In many inflammatory fibrotic diseases, such as Systemic Scleroderma (SSc) and CGVHD with fibrotic features, an abnormal activation of transforming growth factor (TGF $\beta$ ) and platelet-derived growth factor receptor (PDGF-R) pathways have been observed. Tyrosin Kinase Inhibitors (TKIs), which are currently used for treatment of patients with Chronic Myeloid Leukemia (CML), share potent antifibrotic and antiinflammatory properties, being powerful dual inhibitors of both PDGF-R and TGF $\beta$ pathways. Moreover accumulating in vitro data confirm that TKIs, interacting with the TCR and other signalling molecules, carry potent immunomodulatory effects, being involved in both T-cell and B-cell response. Translation to the clinical setting revealed that treatment with Imatinib can achieve encouraging responses in patients with autoimmune diseases and steroid-refractory cGVHD, showing a favourable toxicity profile. While the exact mechanisms leading to such efficacy are still under investigation, use of TKIs in the context of clinical trials should be promoted, aiming to evaluate the biological changes induced in vivo by TKIs and to assess the long term outcome of these patients. Second-generation TKIs, with more favourable toxicity profile are under evaluation in the same setting.

KEYWORDS: cGVHD, Imatinib, TKI 


\section{INTRODUCTION}

Chronic GVHD (cGVHD) is a late complication of allogeneic SCT, previously identified as any GVHD manifestation occurring or lasting more than 100 days after transplantation [1]. Recently, new diagnostic criteria for cGVHD were proposed by the NIH Consensus Conference, based on different clinical manifestations rather than time of onset [2].

cGHVD symptoms are reminiscent of a variety of autoimmune diseases (SSc, Sjögren syndrome, systemic lupus erythematosus, primary biliary cirrhosis, bronchiolitis obliterans, and immune cytopenias). Pathognomic features (i.e., sufficient for establishing a diagnosis) include sclerosis, lichen-planus-like lesions, poikiloderma, esophageal webs, fasciitis, and bronchiolitis obliterans. Skin is the most common site involved in cGVHD at the initial diagnosis in about $75 \%$ of subjects [3]. Pathology of skin lesions is characterized by an intense mononuclear inflammatory infiltrate with destructive changes at the dermalepidermal junction, accompanied by irregular acanthosis, hyperkeratosis, or atrophy, progressing to dermal fibrosis and sclerosis [4]. Other involved organs include mouth, liver, eye, gastrointestinal tract, lung, female genital tract, and joints [3].

Although cGVHD is associated with beneficial graft versus tumor effects and with lower relapse rates, cGVHD is still the major cause for late transplant-related mortality after allogeneic SCT. Indeed, the profound immunosuppression, associated with cGVHD and the immunosuppressive treatment, is responsible for severe infections and secondary malignancies in these patients. As a net effect, in patients receiving SCT for a malignant disorder, there is around a $10 \%$ absolute survival disadvantage at 10 years for those with cGVHD versus those without cGVHD [5, 6].

The main risk factor for cGVHD is the history of a previous acute GVHD (aGVHD) [7]. This association is still evident after reconsidering diagnosis following the new diagnostic criteria proposed by the NIH Consensus Conference. Other specific risk factors for cGVHD include female donor for male recipients, older patient age, and the use of mobilized peripheral blood cells, while the use of mismatched and unrelated donors is a common risk factor both for aGVHD and cGVHD [7].

\subsection{Pathogenetic Pathways Involved in cGVHD}

In allogeneic SCT host immune cells, which are responsible for recognition and rejection of nonselfantigens, are eradicated by conditioning, thus allowing engraftment by donor cells. Host and donor haplotypes can be differently mismatched, and this fact underlies the potential for host-directed immune reaction in GVHD. These circumstances were summarized by Billingham in 1966 in three requisites for the development of GVHD: (I) the graft must contain immunologically competent cells, (II) the recipient must express tissue antigens that are not present in the transplant donor, and (III) the patient must be incapable of mounting an effective response to eliminate the transplanted cells [8]. Subsequent work has tried to better clarify the pathogenetic mechanisms of each of the GVHD syndromes, elucidating the contribution of the different cell lineages of the immune system and soluble mediators.

While it is generally accepted that aGVHD is mainly dependent on donor mature cytotoxic $\mathrm{T}$ lymphocytes, recognizing minor histocompatibility antigens presented by host APC, there are still controversies about the pathogenesis of cGVHD [9, 10]. Direct evidences in humans are difficult to generalize because of the pleomorphic presentation of this syndrome; at the same time, a wide array of cGVHD animal models have been generated, from which significant mechanisms can be hypothesized [1113]. However, two important caveats must be kept in mind while interpreting the results of these models: (I) the kinetics of clinical cGVHD in humans are slower, as they arise in patients who have already been extensively treated with immunosuppressive agents as prophylaxis and/or therapy for acute GVHD; (II) even if clinical cGVHD arises de novo and in the absence of active immunosuppression, it is not possible to definitively rule out the impact of either GVHD prophylaxis and/or subclinical acute GVHD on the subsequent development of cGVHD [14].

Notwithstanding this, three pivotal actors have clearly elucidated in the cGVHD development: T cells, B cells, and profibrotic-inflammatory cytokines. 
T Cells

Donor T cells are certainly necessary for both aGVHD and cGVHD [15]. T cells reactions are directly proportional to the grade of haplotype mismatch, being incompatibility of more than 2 of 8 class HLA I and II loci of major histocompatibility complex (MHC), invariably lethal. T-cell depletion in the haploidentical SCT setting has been shown to circumvent the occurrence of acute and cGVHD [16]. In common circumstances of allogeneic SCT, donor and host mismatches are limited to 7/8 or 8/8 MHC matching, while minor histocompatibility antigens are not screened, and thus, donor and host differ for several alleles.

Similarly, many mouse models of cGVHD are generated by grafting donor bone marrow (BM) cells into a recipient which has the same MHC haplotype but is from a different strain. However, this experimental setting is not specific for cGVHD: only particular combinations of donor/recipient strain result in cGVHD, while other couplings or simply swapping donor/recipient strain could lead to aGVHD; hence, the antigens and the kind of immune response are likely to participate to the determination of the clinical phenotype as well $[11,12]$.

A common theory hypothesizes that cGVHD is a chronicized immune and inflammatory response driven by persistent stimulation by recipient alloantigens. As opposed to aGVHD, the pattern of response relies more on the T CD4+ arm than on CD8+ and is characterized by Th2 cytokines expression. Likewise in some chronic parasitic infection as schistosomiasis, the nature of the microbial antigens and their persistence leads to a polarized Th2 immune response, with emergence of features of chronic inflammation and fibrosis [17].

Alternatively, cGVHD can be considered as a melting pot of different autoimmune diseases, in which the pathogenetic hallmark is the emergence of autoreactive (i.e., recognizing autoantigens as nonself) clones of T and B cells [18]; breaking of tolerance is, however, invariably sustained by autoreactive CD4+ lymphocytes, which are necessary for maintaining and amplifying the autoimmune reaction [19]. Similarly, in cGVHD, a dysfunction of central tolerance has been theorized, based on the evidence of thymic damage, caused by a combination of preparatory regimens, aGVHD and older age (which are indeed risk factor for cGVHD) [20-22]. Experimental confirmation of this hypothesis was provided by a mouse model of thymic dysfunction, in which lethally irradiated $\mathrm{C} 3 \mathrm{H} / \mathrm{HeN}(\mathrm{H}-2 \mathrm{k})$ recipients were reconstituted with $\mathrm{T}$ -

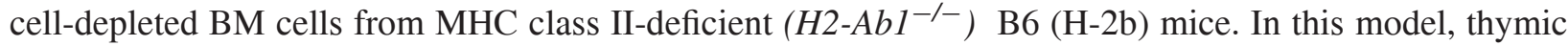
negative selection, which relies on thymic dendritic cells (DC), is crippled, because recipient DC are deleted by conditioning and donor DC are functionally incompetent. This leads to the emergence of donorand recipient-reactive CD4+ clones, which are responsible for a phenotype faithfully reproducing human cGVHD [23].

In 1997, a new population of naturally occurring T CD4+ lymphocytes with fundamental roles in controlling immune responses was discovered ( $\mathrm{T}$ regulatory cells or TReg) [24]. These cells were first identified as bearing high levels of the membrane-bound IL-2Ra (CD25), while subsequent refinement included the expression of the transcriptional regulator FoxP3 and lack of the IL7-Ra chain (CD127) as additional molecular markers $[25,26]$. Absence or defective function of TReg has been correlated with autoimmunity in humans, whereas their presence has been associated with tolerance [27]. TReg have been extensively investigated as potential actors involved in GVHD, with contradictory findings: a positive correlation between high numbers of circulating FOXP3+CD4+CD25hi TReg cells and reduced GVHD incidence has been found in some studies [28, 29], whereas other studies showed inverse correlation $[30,31]$. Also, it remains unclear whether the blood compartment is representative of TReg content and activity in secondary lymphoid organs and target tissues. Frequency of TReg in peripheral tissues was evaluated in only one study, showing a reduced number of these cells in the intestinal mucosa in patients with acute and cGVHD, compared to transplanted patients without GVHD [32].

The ability of TReg to induce antigen-specific suppression aroused a lot of interest as therapeutic option in GVHD. In May 2008, the first patient with steroid-refractory cGVHD with severe lung involvement was treated with adoptive transfer of TReg cells, taken from the donor and expanded ex vivo. 
This treatment achieved not only a reduction of steroids, but also significant improvement in the bronchial obstruction to the level that bronchodilators could be ceased [33].

To date, however, no other reports for specific treatment of cGVHD with TReg infusions have been published.

B Cells

B cells have been recognized for a long time as important players in the pathogenesis of cGVHD [34]. From early reports, occurrence of a variety of auto-Abs was established in cGVHD, of which many already described in rheumatologic conditions [35]. Nevertheless, auto-Abs production does not stand per se as a proof of a pathogenic role for B cells, but, as in similar autoimmune conditions, it could simply represent an epiphenomenon of immune cell activation. However, at least two evidences disagree with this latter interpretation: (I) it was shown that Y chromosome-encoded miHA elicit specific antibody responses following sex-mismatched HSCT, and the presence of these alloantibodies closely correlates with the development of cGVHD, while their reduction after B-cell depleting therapy is associated with clinical response [36, 37]; (II) pathogenetic auto-Abs stimulating PDGF-R have been described in extensive sclerodermatous cGVHD [38] (see next paragraph).

Expansion of autoreactive B cells is thought to be a process relying on the cooperation with $\mathrm{T}$ autoreactive helper who share the same target antigen [19]; however, it has been speculated that in particular conditions, activated B cells can expand and produce IgG without requiring additional antigen stimulation [39]. In cGVHD, inadequate reconstitution of naive B cells is associated with persistence of high levels of the $\mathrm{B}$ cell activating factor (BAFF) that might support antigen-independent expansion of activated CD27+ B cells $[40,41]$.

Moreover, B cells are essential in many functions other than Abs secretion: these include direct antigen-presentation with priming of $\mathrm{T}$ lymphocytes and secretion of cytokines that modulate the intensity and type of immune response [34]. Increased levels of TLR9 expression have been documented in B cells from cGVHD patients, suggesting an improved ability of these cells to act as antigen presenting cells (APCs) and to sustain a chronic inflammatory environment [42].

Last but not least, emerging data show clinical responses from depletion of B cells with Rituximab (RTX), further strengthening the notion of a pathogenic role for B cells in cGVHD (see next paragraph).

\section{Profibrotic-Inflammatory Cytokines}

SSc is an autoimmune disease characterized by chronic inflammation and fibrosis of the target organs [43]. Scleroderma-like changes in cGVHD occur in up to $13 \%-15.5 \%$ of patients [3,44]. Many similarities in the clinical picture and pathological description have been noticed between cGVHD and SSc so that a category of mouse models of cGVHD with scleroderma-like features has been generated to gain insights in the mechanisms of immune-mediated fibrosis, largely contributing also to pathogenetic studies in SSc [11]. Most of these cGVHD models can be achieved by transplanting B10.D2 BM cells into a TBI-conditioned $\mathrm{BALB} / \mathrm{c}$ recipient (the dose of radiation can also affect the severity of disease). This model is MHC matched but differs in numerous minor HLA antigens and results in overt skin and lung fibrosis [45, 46]. CD4+ $\mathrm{T}$ cells are certainly necessary for the disease, but several lines of evidence point to a pivotal role of cytokines, chiefly TGF- $\beta$, in the development of fibrotic changes [47]. McCormick et al. described the temporal sequence of cellular changes and the molecular events occurring in this model: TGF- $\beta-1 \mathrm{mRNA}$ upregulation in the skin and mononuclear cell infiltration, composed by activated monocytes/macrophages and T lymphocytes, are seen as early as a week after BMT and precede detectable increases in collagen mRNA and skin thickening (at day 21) [47, 48]. Administration of anti-pan-TGF- $\beta$ Abs reduced cell infiltrate and reversed skin and lung fibrosis [47]. Effects of TGF- $\beta$, however, were not dependent on the abrogation of immune cell influx, as similar inhibition of fibrosis was achieved with LAP (latencyassociated peptide), a naturally occurring regulator of TGF- $\beta$ bioavailability, residing in the extracellular matrix (ECM), without affecting cutaneous immune cell infiltration [49]. 
Besides TGF- $\beta$, also PDGF has been considered a relevant mediator of fibrosis both in scleroderma and in cGVHD. Our group has recently demonstrated that patients with SSc are characterized by serum stimulatory autoAbs targeting the receptor of platelet-derived growth factor (PDGF-R). Upon engagement of PDGF-R, these Abs activate a downstream signaling cascade (Ha-Ras-ERK 1/2-ROS), composed of HaRas, extracellular-signal-regulated kinases 1 and 2 (ERK 1/2) and reactive oxygen species (ROS). High levels of ROS, in turn, stabilize Ha-Ras, further perpetuating this loop, which ultimately leads to increased collagen gene expression and acquisition of the myofibroblast phenotype [50]. Keeping in mind these data, we subsequently evaluated 19 patients with extensive cGVHD for the presence of stimulatory auto-Abs, directed against the PDGF-R. Stimulatory Abs to the PDGF-R were found selectively in all patients with cGVHD, but in none of the control group of patients without cGVHD. Higher levels were detected in patients with generalized skin involvement and/or lung fibrosis. Abs recognized native PDGF-R, induced tyrosine phosphorylation, accumulation of ROS, and stimulated type 1 collagen gene expression through the Ha-Ras-ERK1/2-ROS loop [38]. Primary fibroblasts derived from SSc and cGVHD patients were found to express chronically higher levels of Ha-Ras with respect to fibroblasts from patients without cGVHD. In line with this observation, it was demonstrated that lentiviral-mediated overexpression of Ha-Ras in mouse skin fibroblasts induced collagen upregulation and conversion to the myofibroblast phenotype [51]. Taken together, these data suggests a role of these auto-Abs in the development of fibrosis and argues for a common pathogenetic trait in cGVDH and SSc phenotypes.

\section{RATIONAL FOR USING TKI IN cGVHD}

\subsection{Treatment Options for Patients with Steroid-Refractory/Dependent cGVHD Are Limited}

Systemic treatment of cGVHD is usually indicated if $\geq 3$ organs are affected or if involvement in any single organ is severe and debilitating. Systemic treatment is also considered for patients with mild overall cGVHD severity if they present characteristics associated with poor prognosis (i.e., platelets below $100,000 / \mathrm{mm}^{3}$, progressive onset) [52].

Data from the Fred Hutchinson Cancer Research Center on patients with cGVHD show that there has not been any significant, meaningful improvement in overall or relapse-free survival from 1980 to 2006 [5]. Up to date steroids (with or without a Calcineurin Inhibitor) are the mainstay for patients with extensive cGVHD, but many patients have a suboptimal response to steroids and are unable to discontinue steroids even after months or years of therapy $[5,53,54]$. Steroid tapering, according to common protocols, is usually slow, exposing patients to substantial side effects. Moreover, in pediatric patients, systemic steroid therapy can be deleterious on a growing child [55]. Finally steroids require monitoring for steroidinduced osteoporosis and diabetes mellitus. Therefore, addition of an effective steroid-sparing agent for these patients is of crucial importance for long-term outcome and for the quality of life (QOL) [56]. Prognosis remains poor for those who do not show any response to first-line treatment (steroid resistant) and those who, although responding, are not able to taper steroids because of flares occurrence (steroiddependent disease). These patients have been considered to have steroid-refractory disease, for which generally accepted criteria are (1) progression on prednisone at $1 \mathrm{mg} / \mathrm{kg} / \mathrm{day}$ for 2 weeks, (2) stable disease on $0.5 \mathrm{mg} / \mathrm{kg} /$ day of prednisone for $4-8$ weeks, and (3) inability to taper prednisone below $0.5 \mathrm{mg} / \mathrm{kg} / \mathrm{day}$ $[57,58]$.

While primary treatment of cGVHD is based on controlled trials, in contrast, evidences for the secondary management of steroid refractory cGVHD are limited almost to phase II trials or retrospective studies. Therefore, it is not surprising that there is no standard approach for steroid refractory cGVHD and these patients should rather be entered on treatment protocols [52, 57].

A number of Phase II trials of secondary agents have been published, reporting encouraging response rates. The most promising results have been achieved with RTX [59-68], ECP (Extracorporeal Photopheresis) [69, 70], and Pentostatin [71]. However, most trials contain relatively few patients with heterogeneous organ involvement and advanced phases of organ manifestations [72-79] (Table 1). 
TABLE 1: Response rate and outcome reported in the main clinical trials for patients with refractory cGVHD.

\begin{tabular}{|c|c|c|c|c|}
\hline 2 nd line treatment & $\begin{array}{c}\text { Response rate } \\
\text { (patients number: } N \text { ) }\end{array}$ & $\begin{array}{l}\text { Organ-specific } \\
\text { response rate }\end{array}$ & Main side effects & References \\
\hline $\begin{array}{l}\text { Mycophenolate } \\
\text { mofetil }\end{array}$ & $\begin{array}{c}46-75 \% \\
N=21-26\end{array}$ & $\begin{array}{c}\text { Skin 53\% }(n=15) \\
\text { Mouth 67\% }(n=15) \\
\text { Liver 54\% }(n=13)\end{array}$ & $\begin{array}{c}\text { Gastrointestinal disturbances } \\
\text { (diarrhea, nausea, and vomiting) }\end{array}$ & {$[72-74]$} \\
\hline $\begin{array}{l}\text { High-dose } \\
\text { cortico-steroids }\end{array}$ & $\begin{array}{c}48 \% \text { major responses } \\
\qquad N=56\end{array}$ & Not Reported & $\begin{array}{l}\text { Infections, diabetes } \\
\text { decompensation, and } \\
\text { psychological effects } \\
\text { (psychosis and insomnia) }\end{array}$ & {$[75]$} \\
\hline $\begin{array}{l}\text { Extracorporeal } \\
\text { photopheresis }\end{array}$ & $\begin{array}{c}61 \% \\
N=71\end{array}$ & $\begin{array}{c}\text { Skin } 40 \%(n=48+17) \\
\text { Sclerotic skin } 67 \%(n=21) \\
\text { Mouth } 77 \%(n=7) \\
\text { Eye } 64 \%(n=4) \\
\text { Lung } 54 \%(n=6) \\
\end{array}$ & $\begin{array}{l}\text { Anemia, requirement for central } \\
\text { IV access }\end{array}$ & {$[69,70]$} \\
\hline Pentostatin & $\begin{array}{l}53 \% \text { major responses } \\
\quad+2 \% \text { minor } \\
\text { responses } N=58 \\
\end{array}$ & $\begin{array}{l}\text { Lichenoid skin } 69 \%(n=39) \\
\text { Sclerotic skin, fascial, and } \\
\text { mouth } 52 \%-57 \%(n=39)\end{array}$ & $\begin{array}{l}\text { Nausea, vomiting, infection, } \\
\text { renal dysfunction, rash, and } \\
\text { headache }\end{array}$ & [71] \\
\hline Tacrolimus & $\begin{array}{c}46 \% \\
N=26\end{array}$ & Not Reported & $\begin{array}{l}\text { Renal dysfunction, thrombotic } \\
\text { microangiopathy, neurotoxicity, } \\
\text { and hypertension }\end{array}$ & [77] \\
\hline Rituximab & $\begin{array}{c}\text { Meta-analysis of } \\
7 \text { studies: OR } 66 \% \\
\text { (CI: } 57-74 \%) \\
N=111\end{array}$ & $\begin{array}{c}\text { Skin } 60 \%(n=67) \\
\text { Oral mucosa } 36 \%(n=46) \\
\text { Liver } 29 \%(n=34) \\
\text { Lung 30\% }(n=14)\end{array}$ & $\begin{array}{l}\text { Infusion reactions, infections, } \\
\text { and hepatitis reactivation }\end{array}$ & [58-68] \\
\hline Sirolimus & $\begin{array}{c}63-94 \% \\
N=16-35\end{array}$ & $\begin{array}{l}\text { Skin } 65 \%(n=29) \\
\text { Mouth } 75 \%(n=8) \\
\text { Liver } 33 \%(n=6) \\
\text { Eye } 64 \%(n=11) \\
\text { GI } 67 \%(n=6)\end{array}$ & $\begin{array}{l}\text { Hypertriglyceridemia, renal } \\
\text { insufficiency, cytopenias, } \\
\text { infections }\end{array}$ & {$[77,78]$} \\
\hline
\end{tabular}

In many studies on second-line treatment of cGVHD, drugs like mycophenolate, sirolimus, or ECP were combined with continuous steroid administration [70, 73, 74, 77-79]. Thus, the contribution of steroids to the reported response rates in these studies remains uncertain. Furthermore, steroid sparing should be an important goal of salvage therapy of cGVHD. Because no predictors of response are yet available either for single immunosuppressive agents or combination therapies, most patients receive empirical treatment in daily clinical practice and changes of therapeutic components in case of lack of response are performed at the individual clinician's discretion [52].

\subsection{TKIs Can Be Safely Administered after Allogeneic SCT}

TKIs are a class of drugs comprising small molecule inhibitors of oncogenic tyrosine kinases (TK), which have recently been developed for treating several malignancies. Among these drugs, Imatinib Mesylate showed a specific inhibitory effect on CML cells and BCR-ABL-transformed cells both in culture and when grown as tumors in mice. Since 1986, phase II clinical trials showed that Imatinib was effective in treating chronic phase CML, and up to date this drug is the most largely used in CML with $\geq 100,000$ patients treated. Imatinib not only inhibits BCR-ABL but also is almost equally potent against PDGFR $\alpha$ and c-KIT receptor tyrosine kinases [80]. c-KIT receptor TK is implicated through activating mutations in GIST [81]; 
indeed, Imatinib and other TKIs are effective also in patients with GIST [82]. Imatinib has also been tested in the treatment of other malignant hematopoietic diseases, including hypereosinophilic syndrome and chronic eosinophilic leukemia, which also express an activated form of PDGFR $\alpha$ [83]. Finally, some reports suggest a limited efficacy of these drugs in patients with systemic mastocytosis with 816 KIT mutations, causing constitutive activation of TK activity of the molecule [84].

More recently, this drug has been also tested in patients with autoimmune diseases and cGVHD (see later).

The acute and chronic safety profile of TKIs has been extensively evaluated in CML patients, and the most studied drug is Imatinib [85]. A common observation is that in patients with early disease, the hematological toxicity is mild, while relevant myelosuppression has been reported in patients with advanced disease [86]. Common extrahematological toxicities that have been reported with Imatinib include nausea, vomiting, diarrhea, fatigue, muscle aches, fluid retention, and skin rash [87]. The concern that Imatinib may lead to more severe toxicities such as cardiac heart failure was first reported by Kerkela et al. [88] Subsequently, the issue of Imatinib-related cardiac toxicity in the non-SCT setting has been addressed by several investigators [89-91]. In each of these reports, cardiac failure and left ventricular dysfunction, which was possibly or probably related to Imatinib therapy, were either not identified [89] or were found to occur rarely (0.04\%/year) as in the International Randomized Study of Interferon and ST1571 trial [90]. In conclusion, since the original report, no further evidence to support an increased risk of cardiac toxicity has emerged with Imatinib [92]. Nilotinib and Dasatinib have a different toxicity profile that has been extensively studied in CML patients [93, 94], but there are still few data regarding the safety of these drugs outside the setting of CML, especially in patients undergoing allogeneic SCT. Some experiences with Imatinib suggest that TKIs use in the peritransplant period had no effect on either TRM or cardiac toxicity, while the potential myelosuppressive effects of Imatinib could be relevant, with conventional doses. Anderlini et al. [95] treated 15 patients who received allogeneic SCT for Ph+ leukemia and doses above $200 \mathrm{mg}$ /day of Imatinib were frequently associated with grade 3-4 cytopenias. In a more recent report focusing the tolerability of Imatinib during the first 90 days after myeloablative allogeneic SCT, Carpenter et al. did not found severe toxicity. When emesis and nausea were not associated with GVHD or infection, symptoms were generally manageable by divided dosing or by antiemetic administration. Although Imatinib may have contributed to transaminase elevations, other temporal associations were noted, including GVHD, infection, and triazole antifungal medication. The same author found that administration of Imatinib do not affect calcineurin inhibitor (Cyclosporin and Tacrolimus) levels [96]. Recent data also suggest the safety of second-generation TKIs, in Ph+ ALL and CML patients who have undergone prior allogeneic SCT.

Dasatinib is a second-generation TKI that inhibits a wider range of tyrosine kinases than Imatinib, including Bcr-Abl and SRC family kinases, and is 300-fold more potent than Imatinib [97]. A phase II study of Dasatinib at $140 \mathrm{mg}$ in patients with Imatinib-resistant or intolerant Ph-ALL, including 15 patients who previously received allogeneic SCT, was reported [98]. However, various adverse events have been observed with the use of Dasatinib, including myelosuppression, bleeding-related events, and fluid retention. Caution should be paid to the possibility of adverse effects of Dasatinib, especially infectious complications and gastrointestinal bleeding [99].

Nilotinib was developed as a more potent and more selective inhibitor of the Bcr-Abl protein, compared to Imatinib. In contrast, the mean IC50 for the inhibition of the phosphorylation of PDGFR $\alpha / \beta$ (in A31 cells) was similar for the 2 drugs $(71 \pm 7 \mathrm{nM}$ and $74 \pm 11 \mathrm{nM})$ and for the inhibition of c-KIT (GIST882 cells) was higher with Nilotinib $(200 \pm 13 \mathrm{nM})$ than with Imatinib $(96 \pm 12 \mathrm{nM})$ [100].

Myelosuppression was reported more frequently in patients with advanced phase CML, but severe clinical consequences such as febrile neutropenia, sepsis, pneumonia, and bleeding associated with thrombocytopenia occurred infrequently. Elevations in serum lipase was reported in a $10 \%$ of patients; these were generally transient and easily managed with brief treatment interruptions. Low grade increases in bilirubin and hepatic transaminases were frequently observed; however, grade 3/4 events occurred very rarely. Nilotinib has demonstrated a modest, dose-related potential for QT interval prolongation, but there 
were no episodes of torsades de pointes observed in patients treated to date. The rates for pleural or pericardial effusions and edema were low both in patients with early phase CML and patients with advanced phase CML [93, 94]. Preliminary data suggest that Nilotinib is well tolerated also in patients who have received an allogenic transplantation [101].

Bosutinib (SKI-606) is an orally active Src and Abl kinase inhibitor presently in Phase III trials for treatment of chronic myelogenous leukaemia (CML) and in Phase II trials for treatment of breast cancer. Recent studies indicate that Bosutinib is active against a broader spectrum of kinases, and these additional inhibitory activities have interesting possibilities for further clinical development [102]. However, clinical data concerning the potential use of this drug in patients with cGVHD are lacking.

\subsection{TKI Have Immunomodulatory Properties by Influencing Different Cell Populations}

TKIs can interfere both with the innate immunity and with the adaptive immune response, interacting with different cell populations: T-cells, B-cells, dendritic cells, mast cells, and macrophages (Figure 1). As TK play a pivotal role in T-cell receptor (TCR) and B-cell receptor (BCR) signal transduction, one can expect that these drugs may also interfere with these processes. Several experiments indeed demonstrate the physiological role of TK in both T-cell and B-cell receptor signal transduction. T-cells lacking functional Abl show decreased interleukin-2 production and cell proliferation in response to the stimulation of Tcell Receptor (TCR) [103]. Moreover Abl phosphorylates the B-cell receptor (BCR), coreceptor CD19, suggesting a role for $\mathrm{Abl}$ also in regulation of B-cell proliferation [104]. According to these observations, Abl knocked-out mice display several defects both in T- and in B-cell development [105]. Finally, the effect on c-KIT may also contribute to an immunomodulating activity of TKIs [106].

Clinical retrospective observations in patients with CML and concomitant autoimmune pathology demonstrated an improvement of clinical autoimmune symptoms during Imatinib treatment [107, 108]. Our preliminary data suggest that immunoglobulins from cGVHD patients, responding to Imatinib treatment, have reduced stimulating activity on quiescent fibroblasts, compared to baseline stimulatory activity (accordingly to the presence of agonistic anti-PDGF-R antibodies) [109]. Furthermore in vitro data indicate that Imatinib potently inhibits diverse cellular responses and interacts with diverse cell subsets, involved both in innate and in the adaptive immunity [110].

T-Cells

Imatinib inhibits DNA synthesis in human T cells stimulated with allogeneic mature dendritic cells but does not induce apoptosis within the concentration range found in CML patients treated with this drug. These effects are dosedependent and have been confirmed in a murine model of delayed-type hypersensitivity $[111,112]$. The consequent reduction of T-cell proliferation may have synergistic effects with other drugs affecting the same pathways, such as some calcineurin inhibitors, and this may be particularly important for TCR-mediated IL-2 production [113].

The interactions between TKIs and T-cells have been recently reviewed by Seggewiss et al. [114]; experimental data indicate that Imatinib, Dasatinib, and Nilotinib exert a direct inhibition of c-Abl and can modulate the related TK in the T-cell signaling pathway. These specific mechanisms include reduced phosphorylation of ZAP-70 and other kinases (LAT, LCK, and ERK1/2) and reduced levels of activated $\mathrm{NF} \kappa \mathrm{B}$. TKIs binds the SRC-family kinase LCK and inhibits the LCK signaling pathway at therapeutically concentrations comparable to that observed in humans receiving TKIs $[111,112,115]$. LCK is a major player in proximal T-cell signaling; TCR-mediated signal transduction leads to activation of the SRC family, TKs LCK and FYN, which are associated with the coreceptors CD4 and CD8 [116]. Activated LCK and/or FYN, in turn, phosphorylate the immunoreceptor tyrosine-based activation motifs (ITAMs), located within the CD3 and $\mathrm{z}$ chains of the TCR/CD3 complex itself. The phosphorylated ITAMs serve as a docking site for ZAP70, which is also a substrate for LCK. ZAP70, in turn, phosphorylates the Tcell-specific adapters LAT and SLP-76, which generate the secondary messenger effectors of T-cell activation and proliferation. (Figure 2). 


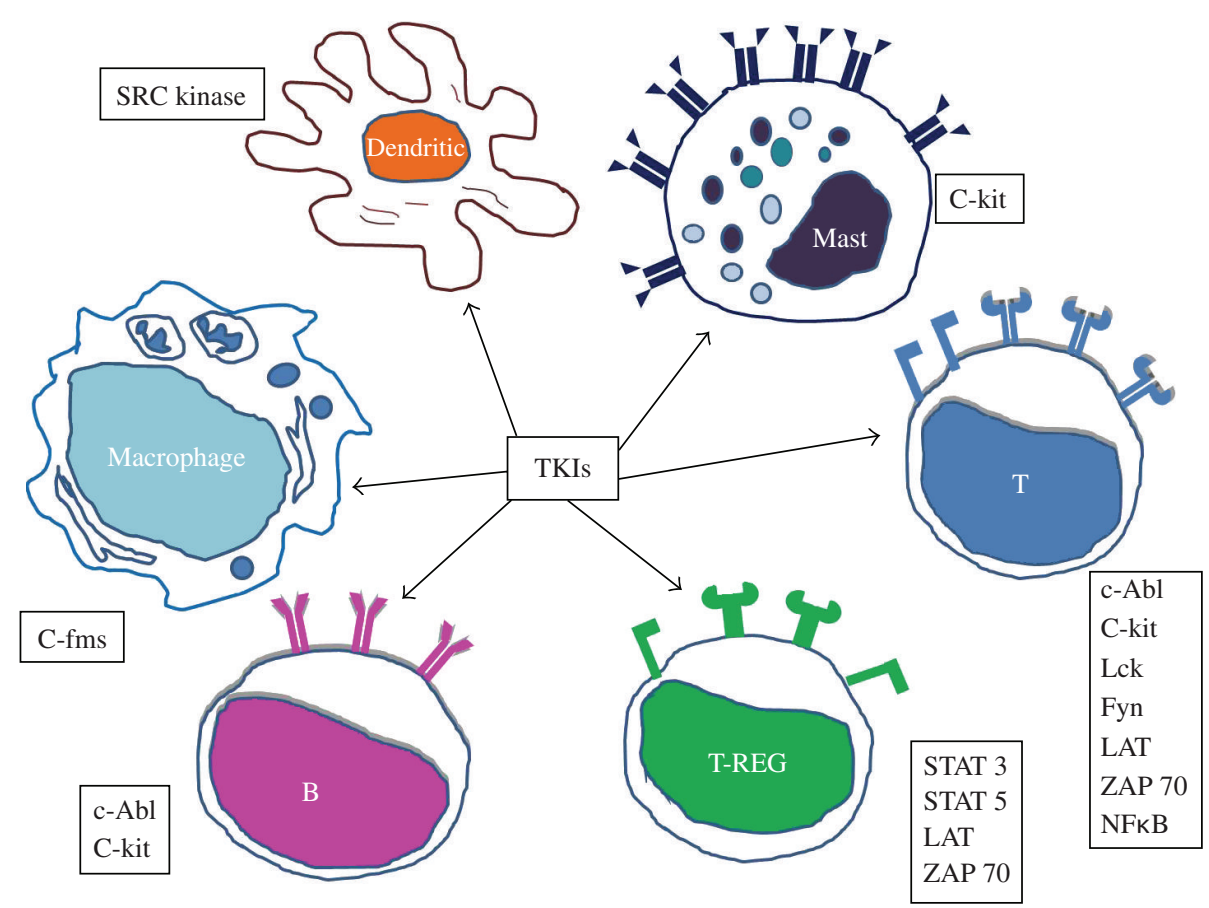

FIGURE 1: TKIs interact with several immune cells* by direct or indirect link to the indicated molecules. *Mast: mast cell; T: T lymphocyte; T-Reg: T regulatory lymphocyte; B: B lymphocyte; Dendritic: Dendritic cell.



FIGURE 2: (A) After linking between TCR and MHC-peptide and after coreceptor CD4 engagement, LCK and Fyn kinases are activated. LCK and Fyn in turn phosphorylate TCR complex and c-ABL. (B) ZAP70 links phosphorylated TCR and is phosphorylated itself by c-abl. So ZAP-70 can phosphorylate other downstream kinases (SLP-76, LAT) to permit T-cell activation and proliferation. P: phosphate; MHC: major histocompatibility complex; T: T-lymphocyte. 
Also, Dasatinib inhibits TCR-mediated signal transduction, cellular proliferation, cytokine production, and in vivo T-cell responses, without inducing apoptosis. Combination with other immune-suppressive agents such as cyclosporine A or rapamycin leads to a much more potent inhibition of T-cell activation, suggesting that targeted inhibition of LCK could be a useful adjunct for enhanced immunomodulation [117]. Because the ability of Dasatinib to inhibit LCK is 1,000-fold higher compared with Imatinib and it also inhibits FYN [118], the immunosuppressive effects of this SRC kinase inhibitor on T cells are likely to be much more profound than those of Imatinib or Nilotinib.

Different T-cell subsets exhibit different thresholds for inhibition, with CD4+ $\mathrm{T}$ cells being marginally more sensitive than CD8 $+\mathrm{T}$ cells and naive $\mathrm{T}$ cells being more sensitive than memory $\mathrm{T}$-cell subsets. This latter observation might reflect differential expression levels of LCK, which plays an important role in proximal signal transduction [119].

\section{T-Regulatory Cells}

As mentioned before, up to date, the role of regulatory cell subsets in cGVHD pathogenesis is still controversial, and, similarly, the role of TKIs in the regulation of this subset is still incompletely characterized. Some in vitro studies show that TReg immunosuppressive function and FoxP3 expression are impaired by therapeutic concentrations of Imatinib, while TReg proliferation is not significantly modified. It has been demonstrated that Imatinib significantly reduces the activation of the transcription factors STAT3 and STAT5 and inhibits phosphorylation of ZAP70 and LAT in TReg [120]. Imatinib treatment in mice decreased TReg frequency and impaired their immunosuppressive function in vivo.

Although the different effects of TKIs at therapeutical concentrations on these pathways deserve further studies, these preliminary observations make TKIs potential candidates as immunomodulatory agents for targeting TReg in cancer immunotherapy or autoimmune diseases. However, the hypothetical mechanisms which could be involved in a possible inhibition of autoreactive or alloreactive clones by TReg, during the administration of TKIs are unclear.

\section{B Cells and Other Immune Populations}

Imatinib blocks c-Abl kinase activity at submicromolar concentrations [121, 122]; consequently, the inhibition of the BCR signalling reduces the B cell proliferation and IgM production in vivo; this can translate in a possible inhibition of the autoreactive B cell responses. Retrospective data show indeed that a relevant proportion of CML patients, treated for a long time with Imatinib, develop hypogammaglobulinemia [123, 124].

DC and donor T-cell interactions, with respect to GVHD in SCT have been recently focused. Src kinases play a central role in DC activation [125, 126], and some studies suggest that Imatinib also negatively affects DC number and function. High concentrations of Imatinib inhibit the development of human CD34+ progenitors and monocytes to DC and hamper the induction of primary Cytotoxic $\mathrm{T}$ Lymphocytes because of low-level expression of costimulatory molecules [127, 128]. However, contradictory results have been reported, as DC treated with Imatinib can also exhibit enhanced APC function and could break the tumor-induced tolerance $[129,130]$. Recent reports have described a new type of immune cell in mice, the "interferon-producing killer dendritic cell" (IKDC). Experimental results indicated that these cells mediate antitumor effects in vivo, both by killing target cells and by subsequently presenting antigens from target cells. These cells might provide a pivotal link between innate and adaptive T-cell immunity $[131,132]$. Interestingly, stimulation of these IKDC subset with imatinib and IL-2 led to infiltration of tumor masses by these cells in a murine model [133]. Whether immune surveillance of tumors is a normal function of IKDC in mice or was induced by Imatinib remains unclear. Furthermore, it is not yet known how Imatinib exerts this effect in mice and whether such properties are transferable to humans. 


\subsection{TKI Have a Potent In Vitro and In Vivo Anti-Inflammatory and Antifibrotic Activity}

Several reports suggest that efficacy of TKI in autoimmune diseases does not rely solely on modulation of adaptive immunity but also on interference with mechanisms of innate immunity and inflammation. Paniagua et al. recently tested Imatinib successfully in an animal model for arthritis [110]. Experimental data suggested that $\mathrm{T}$ cells are influenced by Imatinib only at supratherapeutical levels, while the key effects in this model are mediated by other cell lineages which are more involved in innate immunity and inflammation.

Imatinib could inhibit activation of synovial macrophages and TNF- $\alpha$ production in response to LPS, an effect that could be mediated by c-fms; Imatinib prevented mast cell production of proinflammatory cytokines, probably through blockade of c-kit signaling; finally, in synovial fibroblasts from rheumatoid arthritis patients, Imatinib halted proliferation through $\operatorname{PDGFR} \beta$ [110].

In another study, Imatinib was able to prevent and reverse the development of autoimmune diabetes in the NOD mouse [134]. In the same model, Sunitinib, a multitarget TKI which lacks specificity for cAbl, was equally effective, demonstrating that c-Abl was dispensable for blocking the disease. Additional experiments with another TKI, PLX647 (targeting c-Kit and c-Fms), or an anti-c-Kit mAb showed only marginal efficacy, whereas a soluble form of anti-PDGF-R Ig rapidly reversed diabetes, suggesting that inhibition of PDGF-R is critical to reverse diabetes, suggesting the crucial role of inflammation in this model [135].

The potential of Imatinib and other TKIs as antifibrotic therapeutic agents was initially supported by evidence of efficacy in the mouse model of bleomycin-induced dermal fibrosis. In this model, Imatinib potently reduced the dermal thickness, the number of myofibroblasts, and the collagen content of the skin in a dose-dependent manner and at well-tolerated doses [136, 137]. Similar results were obtained in the same experimental context with Dasatinib and Nilotinib [138]. In this study, the dose range that yields therapeutically relevant concentrations was also identified, which can also be achieved in humans, being for Dasatinib from $3 \mathrm{mg} / \mathrm{kg}$ to $10 \mathrm{mg} / \mathrm{kg}$ and for Nilotinib from $12.5 \mathrm{mg} / \mathrm{kg}$ to $37.5 \mathrm{mg} / \mathrm{kg}$ BID [94, 138-141].

A potent antifibrotic effect of Imatinib was also observed in animal models of pulmonary, renal, cardiac, and liver fibrosis [142-145].

In the clinical setting, Imatinib demonstrated considerable efficacy in various fibrotic disorders [146]. Kay and High [147] reported of two patients with gadolinium-induced nephrogenic systemic fibrosis, who were treated with Imatinib with remarkable improvement and, notably, worsened after cessation of this therapy.

As mentioned later in this paper, Imatinib appears to be highly effective in patients with refractory sclerotic cGVHD. Moreover, several case reports and early phase clinical trials suggested clinical benefit of Imatinib in patients with refractory SSc and mixed connective tissue disease, including progressive skin fibrosis and pulmonary fibrosis [146]. Recently, Spiera et al. [148] published a 1-year open-label clinical trial assessing the safety and efficacy of Imatinib $400 \mathrm{mg} / \mathrm{d}$ in 30 patients with diffuse cutaneous SSc. Twenty-four patients completed 12 months of therapy; after 12 months of treatment, Imatinib improved skin fibrosis, and blinded dermatopathological analysis confirmed a significant decrease in skin thickness and improvement in skin morphology. Lung disease remained stable in patients with interstitial lung disease. Notwithstanding these positive results, a large double-blind, placebo-controlled, randomized trial of Imatinib for idiopathic pulmonary fibrosis in 119 patients did not demonstrate any efficacy for this drug [149].

Preclinical data underscore the peculiarity of Imatinib and other TKIs of exerting an antifibrotic effect that is independent of immunomodulatory and anti-inflammatory activity. In an elegant in vitro model [137], Distler demonstrated that increasing concentrations of Imatinib prevented upregulation of the major extracellular matrix (ECM) proteins COL1A1, COL1A2, and fibronectin 1 in both PDGF- $\beta$ - and TGF- $\beta$ stimulated dermal fibroblasts, at the mRNA level as well as the protein level. While the effect on PDGFstimulated fibroblasts seems to be dependent on inhibition of PDGF-R, blockade of TGF- $\beta$ fibrogenesis is hardly explained by inhibition of TGF- $\beta$ receptors, which are serine-threonine kinases [150]. Nonetheless 
c-Abl, the primary target of Imatinib, turned out to be an important noncanonical mediator of TGF- $\beta$ induced fibrosis, which otherwise is mediated by the classical Smad pathway [151, 152]. Daniels et al. [142] first demonstrated that fibroblasts respond to TGF- $\beta$ by stimulating c-Abl kinase activity independently of Smad2/3 phosphorylation or PDGF-R activation. Moreover, c-Abl was implicated in TGF- $\beta$-induced ECM gene expression, morphologic transformation, and cell proliferation [153,154]. The signaling pathways by which c-Abl mediates such relevant effects on fibrogenesis have been later clarified: Bhattacharyya et al. [154] showed that the induction of early growth response protein 1 (Egr-1) by TGF- $\beta$ is dependent on c-Abl; moreover, $\mathrm{c}-\mathrm{Abl}$ is involved in the phosphorylation/activation of Smad1, which results in the upregulation of CCN2 (connective tissue growth factor) $[155,156]$; c-Abl activates protein kinase $\mathrm{C}(\mathrm{PKC})-\delta$, which in turn decreases binding affinity of the antifibrotic transcription factor Fli1 to the type I collagen promoter, thereby promoting fibrosis [157]; finally, c-Abl was implicated in the reduction of the antifibrotic microRNA miR29 in SSc fibroblasts [158]. Notably, all these pathways were shown to be reversible upon Imatinib addition (Figure 3).

\section{CLINICAL EXPERIENCES WITH TKIS IN cGVHD}

Retrospective data suggest that TKIs administration before and after allogeneic SCT may impact on GVHD development. Some Authors observed a greater incidence of acute GVHD (grade 3-4) and a trend toward less cGVHD in allotransplanted patients, receiving Imatinib for treating relapse of CML [92]. On the contrary, lower incidences of cGVHD in patients who received Imatinib therapy earlier has been described $[112,159-161]$.

The first indications supporting a possible role of TKI in patients with cGVHD came from anecdotal case reports. In 2006, a case of a 33-year-old female was reported, who received allogeneic SCT for CML, developing a steroid-refractory cGVHD, with severe lung involvement, characterized by progressively worsening pulmonary symptoms and severe airway obstruction. As she developed hematological relapse, and donor lymphocyte infusion was contraindicated for the concomitant severe cGVHD, she was treated with Imatinib. Surprisingly, her pulmonary symptoms rapidly improved during the first 2 months of treatment, with gradual elimination of her need for oxygen and considerable improvement in exercise tolerance [162]. In 2008, Magro et al. reported about two patients who developed refractory sclerodermatous cGVHD following allo-SCT and received Imatinib at the dose of $400 \mathrm{mg} / \mathrm{day}$; in both patients, the scleroderma symptoms disappeared within 3 months of initiation of the treatment [163].

Basing on our biological findings, demonstrating the presence of pathogenetic anti-PDGF-R antibodies in patients with cGVHD [38], and on the above-cited preliminary anecdotal reports, we designed a phase I-II study with the primary end point to assess the safety of escalating doses of Imatinib in patients with fibrotic steroid-refractory cGVHD [164]. Imatinib administration was planned for a minimum of 6 months, starting at the initial dose of $100 \mathrm{mg}$ /day. After 1 month, in the absence of severe toxicity or intolerance, the dose was increased to $200 \mathrm{mg}$ /day until the end of the 3rd month; afterwards, if no response had occurred, and in the absence of severe toxicity or intolerance, patients were allowed to receive $400 \mathrm{mg} /$ day.

This first prospective study included nineteen both adult and pediatric patients, affected by steroidrefractory cGvHD, with fibrotic features. The first-line treatment for cGVHD before Imatinib consisted of steroids, while the second line included a miscellanea including RTX, ECP, and Mycophenolate. All patients had a long history of cGVHD (median duration: 37 months) with multiorgan involvement, including skin (17 had scleroderma skin features), lung (11), and sicca syndrome (15 patients), while 8 had other visceral involvement.

Considering the kind of pathological damage in many patients with fibrotic cGVHD, receiving a drug presumably slower than steroids (in terms of mechanism of action), the response has been evaluated in two steps ( 3 and 6 months) in order to observe a possible late clinical improvement in the organs involved by the fibrotic process. 


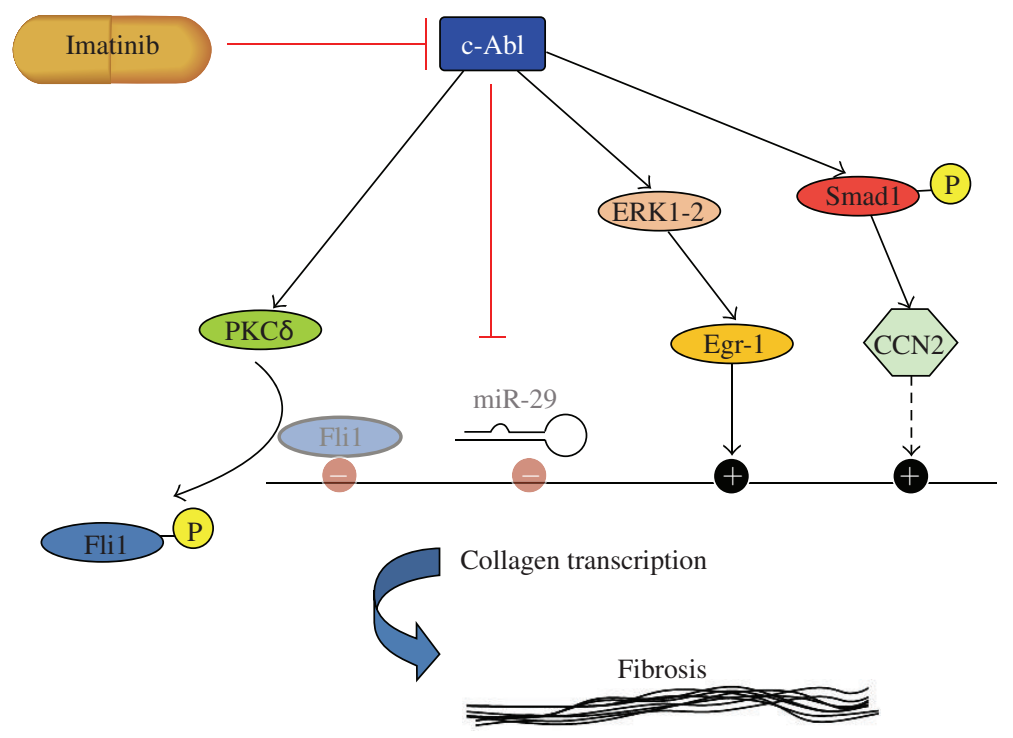

FIGURE 3: Antifibrotic effect of TKI: the original target of Imatinib, c-Abl, is involved in several molecular pathways leading to fibrogenesis. Interference of TKI with other molecules involved in fibrotic pathways (PDGFR and Src kinases) are not illustrated due to required simplification.

Indeed, even though most patients continued Imatinib at the lower dose, the responses significantly improved after 6 months of treatment, with $7 \mathrm{CR}$ and 8 PR (79\% overall response rate), suggesting that in this setting an early discontinuation of the treatment could be detrimental. It is notable that the response to Imatinib allowed in 10 pts to stop or to significantly taper the steroid therapy. The recently updated outcome of these patients suggests a long-term benefit in terms of OS [109] (Figure 4).

A similar study by Magro et al. retrospectively confirmed the activity of Imatinib in 14 patients with heavily pretreated refractory fibrotic cGVHD. Imatinib was started at a median of 44 months after transplantation and was administered for a median of 6 months from time of initiation. With a median followup of 12 months from time of initiation of Imatinib, 29\% of patients had to stop Imatinib because of drug intolerance. Overall, 7 patients responded to Imatinib with 4 patients, improving the Rodnan skin score more than or equal to $90 \%$. Also, in this series, Imatinib therapy allowed for a significant reduction of corticosteroid dosage [165].

Stadler et al. [166] treated with Imatinib 9 patients with refractory cGVHD of the lung. All patients had skin, mucosal, visceral, and/or fasciitic manifestations in addition to pulmonary cGVHD; the median duration of pulmonary cGVHD was 6 months. All patients had already received extensive combination therapies with steroids, calcineurin inhibitors, mycophenolate, and/or ECP. After a median duration of 4 months of treatment, pulmonary function recovered only in 1 patient from severe to moderate, and only 2 patients were able to reduce steroid dosage, whereas 5 patients showed no change, and 2 patients died due to progression of pulmonary GVHD and/or the underlying malignancy. However, it should be observed that 6 of the 9 were given Imatinib for only 1 to 4 months; our experience was more encouraging, as 6 of our 11 patients markedly improved their lung function score, and 2 of them were able to discontinue steroid therapy.

In 2008, we started a second multicenter study to evaluate the safety and the activity of low-dose Imatinib in a larger population of patients with steroid-refractory cGVHD, by using the more stringent response criteria suggested by NIH Consensus Conference for cGVHD [2]. The enrollment has been recently closed, and the interim analysis in the first 24 patients confirms that Imatinib is safe and well tolerated in this setting although the response rate seems to be slightly inferior (48\% at 6 months and $61 \%$ at one year) when compared to the first pilot experience [109]. 


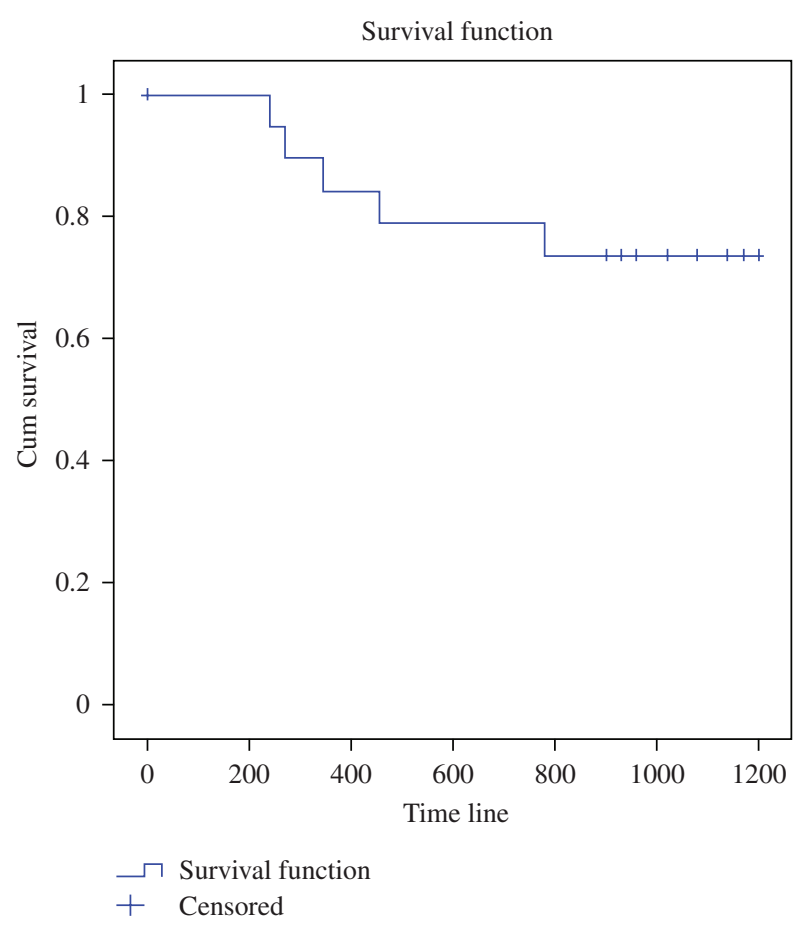

FIGURE 4: Updated OS in 19 patients receiving Imatinib for steroid-refractory cGVHD (Olivieri et al. [109]).

Some possible reasons could be responsible for this discrepancy: first, in this second trial, the response criteria are more stringent (according to those proposed by the NIH Consensus Conference on cGVH); secondly, the average age of the patients enrolled in the second trial was significantly superior (48 years) to the other ones (in the first study, the median age was 29 years, and we observed the best responses in young and pediatric patients). Finally, a different cGVHD pattern was present in the second series, with many patients with both lung involvement and other visceral involvement, and less patients with SSc features or sicca syndrome.

Pooling the data of these two cohorts, 44 patients with cGVHD, refractory to two or more lines of therapy including steroids, have been consecutively treated with Imatinib, by using the same inclusion/exclusion criteria; 29 were male and 15 female, with median age 42 years (range 10-67). The median duration of cGVHD was 23 (range 6-148) months, and all patients received $\geq 2$ lines of therapy, (including 28 previously treated with ECP and 16 with RTX). The main cGVHD targets were represented by lung in 30 patients (Bronchiolitis Obliterans or Pneumonia/fibrosis) and skin in 34 (generalized scleroderma in 21 and localized in 13); 17 patients had Sicca syndrome, 19 other visceral manifestations, and one severe eosinophilic fasciitis; the organ localizations were not mutually exclusive with most patients showing a multiorgan involvement. Overall, the treatment was well tolerated, and we did not observe toxic deaths; the hematological toxicity was mild, with only one patient developing a grade 3 anemia, while the main grade 3-4 extrahematological adverse events were infections or fluid retention. The median duration of treatment was 16 months (range 6-41). Overall, the response rate (excluding the minor responses), evaluated according to the NIH criteria was $62 \%$ at 6 months and $58 \%$ at 12 months after the start of treatment. Among 30 evaluable patients, $43 \%$ of them was able to stop steroids. The best responses have been achieved in patients with skin and gastrointestinal involvement; some measurable degree of lung functional score has been observed in 54\% of patients, but only $29 \%$ of them achieved at least PR; $51 \%$ of patients achieved a measurable improvement of the PS score.

With a median followup of 26 months (8-41), 34 patients are alive and 10 died; 13 patients (29\%) show continuous response without any further treatment. 


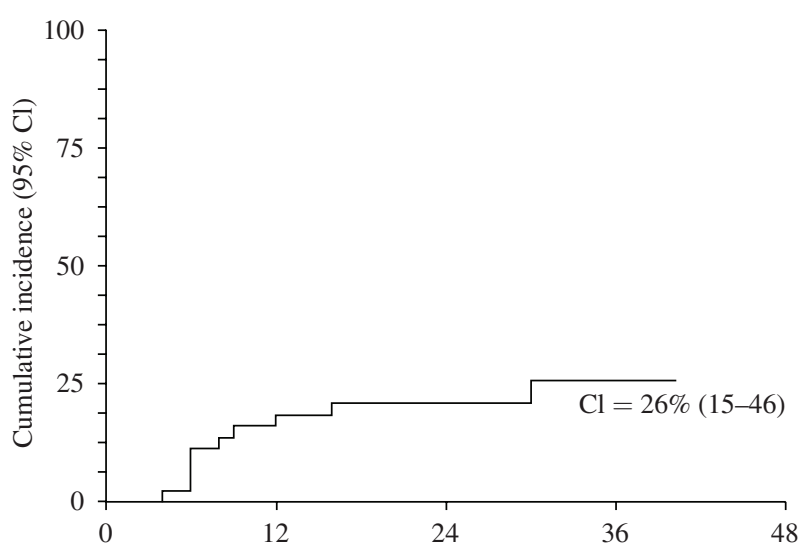

FIGURE 5: Cumulative incidence of treatment failure in 44 consecutive patients, receiving Imatinib for steroid-refractory cGVHD (Olivieri et al. [109]).

The cumulative incidence of treatment failure is $26 \%$ at 3 years, confirming the preliminary data of our first study (Figure 5). Younger patients showed a trend for better OS although the difference is not statistically significant; no differences in OS according to the presence/absence of Skin involvement or the history of previous RTX administration have been observed [109]. Finally, the OS seems not to be different according to the achievement of a major response after 6 months of Imatinib (A. Olivieri, unpublished data).

Preliminary results of the functional test performed in IgG samples from cGVHD patients at baseline confirm the presence of anti-PDGF-R Abs with high ROS stimulating activity (A. Olivieri, unpublished data). Although preliminary, these data also suggest a relationship with the clinical response, with a reduction of ROS output, after the challenge of murine fibroblast with IgG from responding patients [109].

\section{PERSPECTIVES AND CONCLUSIONS}

The biological background and the preliminary clinical data with Imatinib strongly encourage the use of second-generation TKIs in patients with refractory cGVHD. Indeed, the options for patients with steroidrefractory or steroid-dependent cGVHD are limited, including RTX [59-68], Pentostatin [71], and ECP $[69,70]$, but only this latter approach has been validated in a randomized trial; however, this study did not demonstrate any advantage both in OS and in the response rate, outside the improvement of the skin score and the significant steroid sparing [70]. While Pentostatin use in these patients may be associated with several side effects, RTX seems more manageable, and it is not trivial to hypothesize in the future a possible association of this drug with TKIs in these patients, considering the possible synergistic effect on the immune system and their favourable safety profile.

Like Imatinib, Nilotinib is a TKI with better tolerability profile [94, 167], suggesting a better compliance, especially in frail patients such as those with steroid-refractory cGVHD. In vitro models suggest that the PDGF-R inhibitory effect of Nilotinib is at least not inferior than Imatinib and that serum levels, obtained with an oral dose of $400 \mathrm{mg} / \mathrm{die}$ of Imatinib, can achieve an inhibitory effect on fibroblasts activity comparable to that obtained with $800 \mathrm{mg}$ /die of Nilotinib [138]. In our previous experience, patients' frailty and their reduced haematological tolerance heavily limited the daily dose of Imatinib, which was, in more than $80 \%$ of cases, only $100 \mathrm{mg} / \mathrm{die}$ (only one quarter of whole dosage). Therefore, it is reasonable to hypothesize that the better tolerability profile of Nilotinib will allow to treat these cGVHD patients, with a significantly higher dosage; as a consequence, this could allow to achieve a tissue concentration of the drug able to obtain an intracellular anti-PDGFR-effect approximately 4-8 times more potent than that observed with Imatinib administered at $100 \mathrm{mg} /$ die. 
On the basis of this background, we are starting a phase I-II study aimed to evaluate the safety and activity of Nilotinib in patients with steroid-refractory or steroid-dependent cGVHD. A similar approach with Nilotinib has been recently proposed by some EBMT Centers (personal communication).

Other clinical trials with TKIs for patients with cGVHD are ongoing. A US randomized trial (http://Clinicaltrials.gov/ identifier: NCT01309997), in cGVHD patients with skin fibrotic involvement, will evaluate the response rate at 3 and 6 months after Imatinib treatment, compared to RTX, according to the NIH response criteria. Secondary outcome measures are proportion of patients achieving at least $50 \%$ reduction in the daily corticosteroid dose and cumulative incidence of treatment failure.

In conclusion, cGVHD still represents a major challenge for transplanters. Response is often suboptimal, and the consequences of prolonged immune-deficiency expose the patients to infectious complications and secondary malignancies. Indeed, cGVHD is still the leading cause of late nonrelapse mortality in the survivors [56], and the quality of life is strongly compromised also in the responding patients with cGVHD [168]. We have recently shown that patients with scleroderma-like cGVHD have agonistic Abs activating PDGF-R and the biological activity of these autoAbs suggests a pathogenetic role in the development of fibrotic lesions of cGVHD and SSc. These findings argue for a common pathogenic trait in cGVDH and SSc and suggest an alternative therapeutic approach with TKIs as potent dual inhibitors of TGF- $\beta$ and PDGF-R pathways. Moreover, data from animal models and from humans suggest a clinically relevant immunomodulatory activity of TKIs.

The combination of these two properties, together with the acceptable toxicity profile of TKIs, also in the long-term treatment, make them real candidates for the treatment of patients with cGVHD, not only after failure of steroids, but rather to spare the steroid dosage in responding patients, and probably as a component of combined treatments for patients with cGVHD; TKIs can be safely administered in patients receiving Cyclosporin and have been also administered without major problems also in patients under ECP (own unpublished data). Finally, the combination of TKIs with RTX should be explored, considering the favourable safety profile and the potential synergy of these drugs.

Of course, TKIs are unlikely to be the single magic bullet for cGVHD, but the data coming from a particularly difficult setting, such as steroid refractory cGVHD patients, indicate that Imatinib, when used at low doses, is safe and effective. However, the long-term toxicity and the possibility of late-onset effects, correlated to the possible immunosuppressive action of this drug should be carefully evaluated in this particular setting [89]. New TKIs, with better tolerability profile and with more potent antifibrotic and/or immunomodulatory effects, could achieve not only a better response rate, but also could improve the compliance and the duration of treatment in responding patients, with a consequent impact on the long-term outcome of the transplantation procedure.

\section{AKNOWLEDGMENTS}

AIFA (Agenzia Italiana del Farmaco), DOMOS (Donatori di Midollo Osseo), and GITMO centers (Gruppo Italiano per il Trapianto di Midollo Osseo) sponsered this work.

\section{REFERENCES}

[1] S. J. Lee, G. Vogelsang, and M. E. D. Flowers, "Chronic graft-versus-host disease," Biology of Blood and Marrow Transplantation, vol. 9, no. 4, pp. 215-233, 2003.

[2] A. H. Filipovich, D. Weisdorf, S. Pavletic et al., "National institutes of health consensus development project on criteria for clinical trials in chronic graft-versus-host disease: I. diagnosis and staging working group report," Biology of Blood and Marrow Transplantation, vol. 11, no. 12, pp. 945-956, 2005.

[3] S. J. Lee and M. E. Flowers, "Recognizing and managing chronic graft-versus-host disease," Hematology, pp. 134-141, 2008. 
[4] H. M. Shulman, D. Kleiner, S. J. Lee et al., "Histopathologic diagnosis of chronic graft-versus-host disease: National Institutes of Health consensus development project on criteria for clinical trials in chronic graft-versushost disease: II. Pathology working group report," Biology of Blood and Marrow Transplantation, vol. 12, no. 1, pp. 31-47, 2006.

[5] S. J. Lee, "Have we made progress in the management of chronic graft-vs-host disease?" Best Practice and Research, vol. 23, no. 4, pp. 529-535, 2010.

[6] S. Bhatia, L. Francisco, A. Carter et al., "Late mortality after allogeneic hematopoietic cell transplantation and functional status of long-term survivors: report from the Bone Marrow Transplant Survivor study," Blood, vol. 110, no. 10, pp. 3784-3792, 2007.

[7] M. E. D. Flowers, Y. Inamoto, P. A. Carpenter et al., "Comparative analysis of risk factors for acute graft-versushost disease and for chronic graft-versus-host disease according to National Institutes of Health consensus criteria," Blood, vol. 117, pp. 3214-3219, 2011.

[8] R. E. Billingham, "The biology of graft-versus-host reactions," Harvey Lectures, vol. 62, pp. 21-78, 1966.

[9] J. L. M. Ferrara and J. H. Antin, "The pathophysiology of graft-vs.-host disease," in Thomas' Hematopoietic Cell Transplantation, K. G. Blume, S. J. Forman, and F. R. Appelbaum, Eds., pp. 353-368, Blackwell Publishing, Malden, Mass, USA, 3rd edition, 2004.

[10] J. L. Ferrara, J. E. Levine, P. Reddy, and E. Holler, “Graft-versus-host disease,” The Lancet, vol. 373, no. 9674, pp. 1550-1561, 2009.

[11] M. A. Schroeder and J. F. DiPersio, "Mouse models of graft-versus-host disease: advances and limitations," Disease Models \& Mechanisms, vol. 4, pp. 318-333, 2011.

[12] Y. W. Chu and R. E. Gress, "Murine models of chronic graft-versus-host disease: insights and unresolved issues," Biology of Blood and Marrow Transplantation, vol. 14, no. 4, pp. 365-378, 2008.

[13] P. J. Martin, "Biology of chronic graft-versus-host disease: implications for a future therapeutic approach," Keio Journal of Medicine, vol. 57, no. 4, pp. 177-183, 2008.

[14] T. Toubai, Y. Sun, and P. Reddy, "GVHD pathophysiology: is acute different from chronic?" Best Practice \& Research Clinical Haematology, vol. 21, no. 2, pp. 101-117, 2008.

[15] R. Korngold and J. Sprent, "Lethal graft versus host disease after bone marrow transplantation across minor histocompatibility barriers in mice. Prevention by removing mature T cells from marrow," Journal of Experimental Medicine, vol. 148, no. 6, pp. 1687-1698, 1978.

[16] F. Aversa, "Haploidentical haematopoietic stem cell transplantation for acute leukaemia in adults: experience in Europe and the United States," Bone Marrow Transplantation, vol. 41, no. 5, pp. 473-481, 2008.

[17] T. Teshima, T. A. Wynn, R. J. Soiffer, K. I. Matsuoka, and P. J. Martin, "Chronic graft-versus-host disease: how can we release Prometheus?" Biology of Blood and Marrow Transplantation, vol. 14, supplement 1, pp. $142-150,2008$.

[18] A. Tyndall and F. Dazzi, "Chronic GVHD as an autoimmune disease," Best Practice and Research Clinical Haematology, vol. 21, no. 2, pp. 281-289, 2008.

[19] L. Rozendaal, S. T. Pals, E. Gleichmann, and C. J. M. Melief, "Persistence of allospecific helper T cells is required for maintaining autoantibody formation in lupus-like graft-versus-host disease," Clinical and Experimental Immunology, vol. 82, no. 3, pp. 527-532, 1990.

[20] N. Fukushi, H. Arase, B. Wang et al., "Thymus: a direct target tissue in graft-versus-host reaction after allogeneic bone marrow transplantation that results in abrogation of induction of self-tolerance," Proceedings of the National Academy of Sciences of the United States of America, vol. 87, no. 16, pp. 6301-6305, 1990.

[21] T. Ghayur, T. A. Seemayer, A. Xenocostas, and W. S. Lapp, "Complete sequential regeneration of graft-vs.host-induced severely dysplastic thymuses. Implications for the pathogenesis of chronic graft-vs.-host disease," American Journal of Pathology, vol. 133, no. 1, pp. 39-46, 1988.

[22] W. Krenger and G. A. Holländer, "The immunopathology of thymic GVHD," Seminars in Immunopathology, vol. 30, no. 4, pp. 439-456, 2008.

[23] Y. Sakoda, D. Hashimoto, S. Asakura et al., "Donor-derived thymic-dependent T cells cause chronic graftversus-host disease," Blood, vol. 109, no. 4, pp. 1756-1764, 2007.

[24] H. Groux, A. O'Garra, M. Bigler et al., "A CD4+ T-cell subset inhibits antigen-specific T-cell responses and prevents colitis," Nature, vol. 389, no. 6652, pp. 737-742, 1997. 
[25] S. Hori, T. Nomura, and S. Sakaguchi, "Control of regulatory T cell development by the transcription factor Foxp3," Science, vol. 299, no. 5609, pp. 1057-1061, 2003.

[26] N. Seddiki, B. Santner-Nanan, J. Martinson et al., "Expression of interleukin (IL)-2 and IL-7 receptors discriminates between human regulatory and activated T cells," Journal of Experimental Medicine, vol. 203, no. 7, pp. 1693-1700, 2006.

[27] M. G. Roncarolo and M. Battaglia, "Regulatory T-cell immunotherapy for tolerance to self antigens and alloantigens in humans," Nature Reviews Immunology, vol. 7, no. 8, pp. 585-598, 2007.

[28] K. Rezvani, S. Mielke, M. Ahmadzadeh et al., "High donor FOXP3-positive regulatory T-cell (Treg) content is associated with a low risk of GVHD following HLA-matched allogeneic SCT," Blood, vol. 108, no. 4, pp. 1291-1297, 2006.

[29] E. Zorn, H. T. Kim, S. J. Lee et al., "Reduced frequency of FOXP3+ CD4+CD25+ regulatory T cells in patients with chronic graft-versus-host disease," Blood, vol. 106, no. 8, pp. 2903-2911, 2005.

[30] Y. Miura, C. J. Thoburn, E. C. Bright et al., "Association of Foxp3 regulatory gene expression with graft-versushost disease," Blood, vol. 104, no. 7, pp. 2187-2193, 2004.

[31] F. J. Clark, R. Gregg, K. Piper et al., "Chronic graft-versus-host disease is associated with increased numbers of peripheral blood CD4+CD25high regulatory T cells," Blood, vol. 103, no. 6, pp. 2410-2416, 2004.

[32] K. Rieger, C. Loddenkemper, J. Maul et al., "Mucosal FOXP3+ regulatory T cells are numerically deficient in acute and chronic GvHD," Blood, vol. 107, no. 4, pp. 1717-1723, 2006.

[33] P. Trzonkowski, M. Bieniaszewska, J. Juscinska et al., "First-in-man clinical results of the treatment of patients with graft versus host disease with human ex vivo expanded CD4+CD25+CD127- T regulatory cells," Clinical Immunology, vol. 133, no. 1, pp. 22-26, 2009.

[34] A. Shimabukuro-Vornhagen, M. J. Hallek, R. F. Storb, and M. S. von Bergwelt-Baildon, "The role of B cells in the pathogenesis of graft-versus-host disease," Blood, vol. 114, no. 24, pp. 4919-4927, 2009.

[35] R. Kapur, S. Ebeling, and A. Hagenbeek, "B-cell involvement in chronic graft-versus-host disease," Haematologica, vol. 93, no. 11, pp. 1702-1711, 2008.

[36] E. Zorn, D. B. Miklos, B. H. Floyd et al., "Minor histocompatibility antigen DBY elicits a coordinated B and T cell response after allogeneic stem cell transplantation," Journal of Experimental Medicine, vol. 199, no. 8, pp. 1133-1142, 2004.

[37] D. B. Miklos, H. T. Kim, K. H. Miller et al., "Antibody responses to H-Y minor histocompatibility antigens correlate with chronic graft-versus-host disease and disease remission," Blood, vol. 105, no. 7, pp. 2973-2978, 2005.

[38] S. Svegliati, A. Olivieri, N. Campelli et al., "Stimulatory autoantibodies to PDGF receptor in patients with extensive chronic graft-versus-host disease," Blood, vol. 110, no. 1, pp. 237-241, 2007.

[39] M. Thien, T. G. Phan, S. Gardam et al., "Excess BAFF rescues self-reactive B cells from peripheral deletion and allows them to enter forbidden follicular and marginal zone niches," Immunity, vol. 20, no. 6, pp. 785-798, 2004.

[40] S. Sarantopoulos, K. E. Stevenson, H. T. Kim et al., "High levels of B-cell activating factor in patients with active chronic graft-versus-host disease," Clinical Cancer Research, vol. 13, no. 20, pp. 6107-6114, 2007.

[41] S. Sarantopoulos, K. E. Stevenson, H. T. Kim et al., "Altered B-cell homeostasis and excess BAFF in human chronic graft-versus-host disease," Blood, vol. 113, no. 16, pp. 3865-3874, 2009.

[42] K. She, A. L. Gilman, S. Aslanian et al., "Altered Toll-like receptor 9 responses in circulating B cells at the onset of extensive chronic graft-versus-host disease," Biology of Blood and Marrow Transplantation, vol. 13, no. 4, pp. 386-397, 2007.

[43] A. Gabrielli, E. V. Avvedimento, and T. Krieg, "Scleroderma," The New England Journal of Medicine, vol. 360, no. 19, pp. 1989-2003, 2009.

[44] C. Skert, F. Patriarca, A. Sperotto et al., "Sclerodermatous chronic graft-versus-host disease after allogeneic hematopoietic stem cell transplantation: incidence, predictors and outcome," Haematologica, vol. 91, no. 2, pp. 258-261, 2006.

[45] B. D. Jaffee and H. N. Claman, "Chronic graft-versus-host disease (GVHD) as a model for scleroderma. I. Description of model systems," Cellular Immunology, vol. 77, no. 1, pp. 1-12, 1983. 
[46] Y. DeClerck, V. Draper, and R. Parkman, "Clonal analysis of murine graft-vs-host disease. II leukokines that stimulate fibroblast proliferation and collagen synthesis in graft-vs. host disease," Journal of Immunology, vol. 136, no. 10, pp. 3549-3552, 1986.

[47] L. L. McCormick, Y. Zhang, E. Tootell, and A. C. Gilliam, "Anti-TGF-beta treatment prevents skin and lung fibrosis in murine sclerodermatous graft-versus-host disease: a model for human scleroderma," Journal of Immunology, vol. 163, no. 10, pp. 5693-5699, 1999.

[48] Y. Zhang, L. L. McCormick, and A. C. Gilliam, "Murine sclerodermatous graft-versus-host disease, a model for human scleroderma: cutaneous cytokines, chemokines, and immune cell activation," Journal of Immunology, vol. 168, no. 6, pp. 3088-3098, 2002.

[49] Y. Zhang, L. L. McCormick, and A. C. Gilliam, "Latency-associated peptide prevents skin fibrosis in murine sclerodermatous graft-versus-host disease, a model for human scleroderma," Journal of Investigative Dermatology, vol. 121, no. 4, pp. 713-719, 2003.

[50] S. S. Baroni, M. Santillo, F. Bevilacqua et al., "Stimulatory autoantibodies to the PDGF receptor in systemic sclerosis," The New England Journal of Medicine, vol. 354, no. 25, pp. 2667-2676, 2006.

[51] S. Smaldone, J. Olivieri, G. L. Gusella, G. Moroncini, A. Gabrielli, and F. Ramirez, "Ha-Ras stabilization mediates pro-fibrotic signals in dermal fibroblasts," Fibrogenesis Tissue Repair, vol. 4, article 8, 2011.

[52] D. Wolff, A. Gerbitz, F. Ayuk et al., "Consensus conference on clinical practice in chronic graft-versushost disease (GVHD): first-line and topical treatment of chronic GVHD," Biology of Blood and Marrow Transplantation, vol. 16, no. 12, pp. 1611-1628, 2010.

[53] G. B. Vogelsang, "How I treat chronic graft-versus-host disease," Blood, vol. 97, no. 5, pp. 1196-1201, 2001.

[54] S. Koc, W. Leisenring, M. E. D. Flowers et al., "Therapy for chronic graft-versus-host disease: a randomized trial comparing cyclosporine plus prednisone versus prednisone alone," Blood, vol. 100, no. 1, pp. 48-51, 2002.

[55] K. Baird, K. Cooke, and K. R. Schultz, "Chronic graft-versus-host disease (GVHD) in children," Pediatric Clinics of North America, vol. 57, no. 1, pp. 297-322, 2010.

[56] G. Socie, J. Ritz, and P. J. Martin, "Current challenges in chronic graft-versus-host disease," Biology of Blood and Marrow Transplantation, vol. 16, supplement 1, pp. S146-S151, 2010.

[57] D. Wolff, M. Schleuning, S. von Harsdorf et al., "Consensus conference on clinical practice in chronic GVHD: second-line Treatment of chronic graft-versus-host disease," Biology of Blood and Marrow Transplantation, vol. 17, pp. 1-17, 2010.

[58] M. Berger, E. Biasin, F. Saglio, and F. Fagioli, "Innovative approaches to treat steroid-resistant or steroid refractory GVHD," Bone Marrow Transplantation, vol. 42, supplement 2, pp. S101-S105, 2008.

[59] C. Cutler, D. Miklos, H. T. Kim et al., "Rituximab for steroid-refractory chronic graft-versus-host disease," Blood, vol. 108, no. 2, pp. 756-762, 2006.

[60] A. M. Carella, S. Biasco, S. Nati, A. Congiu, and E. Lerma, "Rituximab is effective for extensive steroidrefractory chronic graft-vs.-host-disease," Leukemia and Lymphoma, vol. 48, no. 3, pp. 623-624, 2007.

[61] M. Mohty, N. Marchetti, J. El Cheikh, C. Faucher, S. Furst, and D. Blaise, "Rituximab as salvage therapy for refractory chronic GVHD," Bone Marrow Transplantation, vol. 41, no. 10, pp. 909-911, 2008.

[62] M. Okamoto, A. Okano, S. Akamatsu et al., "Rituximab is effective for steroid-refractory sclerodermatous chronic graft-versus-host disease," Leukemia, vol. 20, no. 1, pp. 172-173, 2006.

[63] T. Teshima, K. Nagafuji, H. Henzan et al., "Rituximab for the treatment of corticosteroid-refractory chronic graft-versus-host disease," International Journal of Hematology, vol. 90, no. 2, pp. 253-260, 2009.

[64] M. R. Canninga-Van Dijk, H. M. van der Straaten, R. Fijnheer, C. J. Sanders, J. G. Van Den Tweel, and L. F. Verdonck, "Anti-CD20 monoclonal antibody treatment in 6 patients with therapy-refractory chronic graftversus-host disease," Blood, vol. 104, no. 8, pp. 2603-2606, 2004.

[65] V. Ratanatharathorn, L. Ayash, C. Reynolds et al., "Treatment of chronic graft-versus-host disease with antiCD20 chimeric monoclonal antibody," Biology of Blood and Marrow Transplantation, vol. 9, no. 8, pp. 505$511,2003$.

[66] F. Zaja, A. Bacigalupo, F. Patriarca et al., "Treatment of refractory chronic GVHD with rituximab: a GITMO study," Bone Marrow Transplantation, vol. 40, no. 3, pp. 273-277, 2007.

[67] M. Von Bonin, U. Oelschlagel, J. Radke et al., "Treatment of chronic steroid-refractory graft-versus-host disease with low-dose rituximab," Transplantation, vol. 86, no. 6, pp. 875-879, 2008. 
[68] M. A. Kharfan-Dabaja, A. R. Mhaskar, B. Djulbegovic, C. Cutler, M. Mohty, and A. Kumar, "Efficacy of rituximab in the setting of steroid-refractory chronic graft-versus-host disease: a systematic review and metaanalysis," Biology of Blood and Marrow Transplantation, vol. 15, no. 9, pp. 1005-1013, 2009.

[69] D. R. Couriel, C. Hosing, R. Saliba et al., "Extracorporeal photochemotherapy for the treatment of steroidresistant chronic GVHD," Blood, vol. 107, no. 8, pp. 3074-3080, 2006.

[70] M. E. D. Flowers, J. F. Apperley, K. van Besien et al., "A multicenter prospective phase 2 randomized study of extracorporeal photopheresis for treatment of chronic graft-versus-host disease," Blood, vol. 112, no. 7, pp. 2667-2674, 2008.

[71] D. A. Jacobsohn, A. R. Chen, M. Zahurak et al., "Phase II study of pentostatin in patients with corticosteroidrefractory chronic graft-versus-host disease," Journal of Clinical Oncology, vol. 25, no. 27, pp. 4255-4261, 2007.

[72] B. Mookerjee, V. Altomonte, and G. Vogelsang, "Salvage therapy for refractory chronic graft-versus-host disease with mycophenolate mofetil and tacrolimus," Bone Marrow Transplantation, vol. 24, no. 5, pp. 517-520, 1999.

[73] F. Lopez, P. Parker, A. Nademanee et al., "Efficacy of mycophenolate mofetil in the treatment of chronic graftversus-host disease," Biology of Blood and Marrow Transplantation, vol. 11, no. 4, pp. 307-313, 2005.

[74] A. Busca, F. Locatelli, F. Marmont, E. Audisia, and M. Falda, "Response to mycophenolate mofetil therapy for refractory chronic graft-versus-host disease," Haematologica, vol. 88, no. 7, pp. 837-839, 2003.

[75] G. Akpek, S. M. Lee, V. Anders, and G. B. Vogelsang, "A high-dose pulse steroid regimen for controlling active chronic graft-versus-host disease," Biology of Blood and Marrow Transplantation, vol. 7, no. 9, pp. 495-502, 2001.

[76] A. Kanamaru, Y. Takemoto, E. Kakishita et al., "FK506 treatment of graft-versus-host disease developing or exacerbating during prophylaxis and therapy with cyclosporin and/or other immunosuppressants. Japanese FK506 BMT study group," Bone Marrow Transplantation, vol. 15, no. 6, pp. 885-889, 1995.

[77] D. R. Couriel, R. Saliba, M. P. Escalan et al., "Sirolimus in combination with tacrolimus and corticosteroids for the treatment of resistant chronic graft-versus-host disease," British Journal of Haematology, vol. 130, no. 3, pp. 409-417, 2005.

[78] L. J. Johnston, J. Brown, J. A. Shizuru et al., "Rapamycin (sirolimus) for treatment of chronic graft-versus-host disease," Biology of Blood and Marrow Transplantation, vol. 11, no. 1, pp. 47-55, 2005.

[79] H. T. Greinix, B. Volc-Platzer, P. Kalhs et al., "Extracorporeal photochemotherapy in the treatment of severe steroid-refractory acute graft-versus-host disease: a pilot study," Blood, vol. 96, no. 7, pp. 2426-2431, 2000.

[80] E. Buchdunger, C. L. Cioffi, N. Law et al., "Abl protein-tyrosine kinase inhibitor STI571 inhibits in vitro signal transduction mediated by c-Kit and platelet-derived growth factor receptors," Journal of Pharmacology and Experimental Therapeutics, vol. 295, no. 1, pp. 139-145, 2000.

[81] M. C. Heinrich, C. L. Corless, A. Duensing et al., "PDGFRA activating mutations in gastrointestinal stromal tumors," Science, vol. 299, no. 5607, pp. 708-710, 2003.

[82] G. D. Demetri, M. von Mehren, C. D. Blanke et al., "Efficacy and safety of imatinib mesylate in advanced gastrointestinal stromal tumors," The New England Journal of Medicine, vol. 347, no. 7, pp. 472-480, 2002.

[83] T. Hunter, "Treatment for chronic myelogenous leukemia: the long road to imatinib," Journal of Clinical Investigation, vol. 117, no. 8, pp. 2036-2043, 2007.

[84] C. Ustun, D. L. Deremer, and C. Akin, "Tyrosine kinase inhibitors in the treatment of systemic mastocytosis," Leukemia Research, vol. 35, no. 9, pp. 1143-1152, 2011.

[85] B. J. Druker, F. Guilhot, S. G. O’Brien et al., "Five-year follow-up of patients receiving imatinib for chronic myeloid leukemia," The New England Journal of Medicine, vol. 355, no. 23, pp. 2408-2417, 2006.

[86] A. Hochhaus, B. Druker, C. Sawyers et al., "Favorable long-term follow-up results over 6 years for response, survival, and safety with imatinib mesylate therapy in chronic-phase chronic myeloid leukemia after failure of interferon-alpha treatment," Blood, vol. 111, no. 3, pp. 1039-1043, 2008.

[87] M. H. Cohen, J. R. Johnson, and R. Pazdur, "U.S. food and drug administration drug approval summary: conversion of imatinib mesylate (STI571; Gleevec) tablets from accelerated approval to full approval," Clinical Cancer Research, vol. 11, no. 1, pp. 12-19, 2005.

[88] R. Kerkela, L. Grazette, R. Yacobi et al., "Cardiotoxicity of the cancer therapeutic agent imatinib mesylate," Nature Medicine, vol. 12, no. 8, pp. 908-916, 2006. 
[89] C. Gambacorti, L. Tornaghi, A. Franceschino, R. Piazza, G. Corneo, and E. Pogliani, "In reply to "cardiotoxicity of the cancer therapeutic agent imatinib mesylate'," Nature Medicine, vol. 13, no. 1, pp. 13-14, 2007.

[90] A. Hatfield, S. Owen, and P. R. Pilot, "In reply to 'Cardiotoxicity of the cancer therapeutic agent imatinib mesylate'," Nature Medicine, vol. 13, no. 1, pp. 13-16, 2007.

[91] E. Atallah, J. B. Durand, H. Kantarjian, and J. Cortes, "Congestive heart failure is a rare event in patients receiving imatinib therapy," Blood, vol. 110, no. 4, pp. 1233-1237, 2007.

[92] M. J. Burke, B. Trotz, X. Luo et al., "Imatinib use either pre- or post-allogeneic hematopoietic cell transplantation (allo-HCT) does not increase cardiac toxicity in chronic myelogenous leukemia patients," Bone Marrow Transplantation, vol. 44, no. 3, pp. 169-174, 2009.

[93] F. J. Giles, M. O'Dwyer, and R. Swords, "Class effects of tyrosine kinase inhibitors in the treatment of chronic myeloid leukemia," Leukemia, vol. 23, no. 10, pp. 1698-1707, 2009.

[94] H. Kantarjian, F. Giles, L. Wunderle et al., "Nilotinib in imatinib-resistant CML and Philadelphia chromosomepositive ALL," The New England Journal of Medicine, vol. 354, no. 24, pp. 2542-2551, 2006.

[95] P. Anderlini, S. Sheth, K. Hicks, C. Ippoliti, S. Giralt, and R. E. Champlin, "Re: imatinib mesylate administration in the first 100 days after stem cell transplantation," Biology of Blood and Marrow Transplantation, vol. 10, no. 12, pp. 883-884, 2004.

[96] P. A. Carpenter, D. S. Snyder, M. E. D. Flowers et al., "Prophylactic administration of imatinib after hematopoietic cell transplantation for high-risk Philadelphia chromosome-positive leukemia," Blood, vol. 109, no. 7, pp. 2791-2793, 2007.

[97] A. Olivieri and L. Manzione, "Dasatinib: a new step in molecular target therapy," Annals of Oncology, vol. 18, supplement 6, pp. 542-546, 2007.

[98] O. Ottmann, H. Dombret, G. Martinelli et al., "Dasatinib induces rapid hematologic and cytogenetic responses in adult patients with Philadelphia chromosome-positive acute lymphoblastic leukemia with resistance or intolerance to imatinib: interim results of a phase 2 study," Blood, vol. 110, no. 7, pp. 2309-2315, 2007.

[99] H. J. Khoury, F. Guilhot, T. P. Hughes, D. W. Kim, and J. E. Cortes, "Dasatinib treatment for Philadelphia chromosome-positive leukemias: practical considerations," Cancer, vol. 115, no. 7, pp. 1381-1394, 2009.

[100] E. Weisberg, P. W. Manley, W. Breitenstein et al., "Characterization of AMN107, a selective inhibitor of native and mutant Bcr-Abl," Cancer Cell, vol. 7, no. 2, pp. 129-141, 2005.

[101] S. Merante, A. A. Colombo, S. Calatroni et al., "Nilotinib restores long-term full-donor chimerism in Ph-positive acute lymphoblastic leukemia relapsed after allogeneic transplantation," Bone Marrow Transplantation, vol. 44, no. 4, pp. 263-264, 2009.

[102] F. Boschelli, K. Arndt, and C. Gambacorti-Passerini, "Bosutinib: a review of preclinical studies in chronic myelogenous leukaemia," European Journal of Cancer, vol. 46, no. 10, pp. 1781-1789, 2010.

[103] P. A. Zipfel, W. Zhang, M. Quiroz, and A. M. Pendergast, "Requirement for Abl kinases in T cell receptor signaling," Current Biology, vol. 14, no. 14, pp. 1222-1231, 2004.

[104] P. A. Zipfel, M. Grove, K. Blackburn, M. Fujimoto, T. F. Tedder, and A. M. Pendergast, "The c-Abl tyrosine kinase is regulated downstream of the B cell antigen receptor and interacts with CD19," Journal of Immunology, vol. 165, no. 12, pp. 6872-6879, 2000.

[105] V. L. J. Tybulewicz, C. E. Crawford, P. K. Jackson, R. T. Bronson, and R. C. Mulligan, "Neonatal lethality and lymphopenia in mice with a homozygous disruption of the c-abl proto-oncogene," Cell, vol. 65, no. 7, pp. 1153-1163, 1991.

[106] V. Agosti, S. Corbacioglu, I. Ehlers et al., "Critical role for Kit-mediated Src kinase but not PI 3-kinase signaling in pro T and pro B cell development," Journal of Experimental Medicine, vol. 199, no. 6, pp. 867-878, 2004.

[107] K. Miyachi, A. Ihara, R. W. Hankins, R. Murai, S. Maehiro, and H. Miyashita, "Efficacy of imatinib mesylate (STI571) treatment for a patient with rheumatoid arthritis developing chronic myelogenous leukemia," Clinical Rheumatology, vol. 22, no. 4-5, pp. 329-332, 2003.

[108] K. K. Eklund and H. Joensuu, "Treatment of rheumatoid arthritis with imatinib mesylate: clinical improvement in three refractory cases," Annals of Medicine, vol. 35, no. 5, pp. 362-367, 2003.

[109] A. Olivieri, M. Cimminiello, F. Locatelli et al., "Imatinib is safe and effective in patients with refractory Chronic Graft Versus Host Disease: analysis of two consecutive prospective GITMO studies," Blood, vol. 116, article $246,2010$. 
[110] R. T. Paniagua, O. Sharpe, P. P. Ho et al., "Selective tyrosine kinase inhibition by imatinib mesylate for the treatment of autoimmune arthritis," Journal of Clinical Investigation, vol. 116, no. 10, pp. 2633-2642, 2006.

[111] A. B. Dietz, L. Souan, G. J. Knutson, P. A. Bulur, M. R. Litzow, and S. Vuk-Pavlović, "Imatinib mesylate inhibits T-cell proliferation in vitro and delayed-type hypersensitivity in vivo," Blood, vol. 104, no. 4, pp. 1094-1099, 2004.

[112] R. Seggewiss, K. Lore, E. Greiner et al., "Imatinib inhibits T-cell receptor-mediated T-cell proliferation and activation in a dose-dependent manner," Blood, vol. 105, no. 6, pp. 2473-2479, 2005.

[113] S. Ho, N. Clipstone, L. Timmermann et al., "The mechanism of action of cyclosporin A and FK506," Clinical Immunology and Immunopathology, vol. 80, no. 3, pp. S40-S45, 1996.

[114] R. Seggewiss, D. A. Price, and M. A. Purbhoo, "Immunomodulatory effects of imatinib and second-generation tyrosine kinase inhibitors on T cells and dendritic cells: an update," Cytotherapy, vol. 10, no. 6, pp. 633-641, 2008.

[115] K. Cwynarksi, R. Laylor, E. Macchiarulo et al., "Imatinib inhibits the activation and proliferation of normal T lymphocytes in vitro," Leukemia, vol. 18, no. 8, pp. 1332-1339, 2004.

[116] R. Zamoyska, A. Basson, A. Filby, G. Legname, M. Lovatt, and B. Seddon, "The influence of the src-family kinases, Lck and Fyn, on T cell differentiation, survival and activation," Immunological Reviews, vol. 191, pp. 107-118, 2003.

[117] A. E. Schade, G. L. Schieven, R. Townsend et al., "Dasatinib, a small-molecule protein tyrosine kinase inhibitor, inhibits T-cell activation and proliferation,” Blood, vol. 111, no. 3, pp. 1366-1377, 2008.

[118] J. Das, P. Chen, D. Norris et al., "2-aminothiazole as a novel kinase inhibitor template Structureactivity relationship studies toward the discovery of N-(2-chloro-6-methylphenyl)-2-[[6-[4-(2-hydroxyethyl)1- piperazinyl)]-2-methyl-4-pyrimidinyl]amino)]-1,3-thiazole-5-carboxamide (dasatinib, BMS-354825) as a potent pan-Src kinase inhibitor," Journal of Medicinal Chemistry, vol. 49, no. 23, pp. 6819-6832, 2006.

[119] R. Weichsel, C. Dix, L. Wooldridge et al., "Profound inhibition of antigen-specific T-cell effector functions by dasatinib," Clinical Cancer Research, vol. 14, no. 8, pp. 2484-2491, 2008.

[120] N. Larmonier, N. Janikashvili, C. J. Lacasse et al., "Imatinib mesylate inhibits CD4+CD25+ regulatory T cell activity and enhances active immunotherapy against BCR-ABL- tumors," Journal of Immunology, vol. 181, no. 10, pp. 6955-6963, 2008.

[121] E. Buchdunger, A. Matter, and B. J. Druker, "Bcr-Abl inhibition as a modality of CML therapeutics," Biochimica et Biophysica Acta, vol. 1551, pp. M11-M18, 2001.

[122] M. A. Fabian, W. H. Biggs III, D. K. Treiber et al., "A small molecule-kinase interaction map for clinical kinase inhibitors," Nature Biotechnology, vol. 23, no. 3, pp. 329-336, 2005.

[123] R. Santachiara, R. Maffei, S. Martinelli et al., "Development of hypogammaglobulinemia in patients treated with imatinib for chronic myeloid leukemia or gastrointestinal stromal tumor," Haematologica, vol. 93, no. 8, pp. 1252-1255, 2008.

[124] J. L. Steegmann, G. Moreno, C. Aláez et al., "Chronic myeloid leukemia patients resistant to or intolerant of interferon alpha and subsequently treated with imatinib show reduced immunoglobulin levels and hypogammaglobulinemia," Haematologica, vol. 88, no. 7, pp. 762-768, 2003.

[125] G. Napolitani, N. Bortoletto, L. Racioppi, A. Lanzavecchia, and U. D’Oro, “Activation of src-family tyrosine kinases by LPS regulates cytokine production in dendritic cells by controlling AP-1 formation," European Journal of Immunology, vol. 33, no. 10, pp. 2832-2841, 2003.

[126] C. L. Chu and C. A. Lowell, "The Lyn tyrosine kinase differentially regulates dendritic cell generation and maturation," Journal of Immunology, vol. 175, no. 5, pp. 2880-2889, 2005.

[127] S. Appel, A. M. Boehmler, F. Grünebach et al., "Imatinib mesylate affects the development and function of dendritic cells generated from CD34+ peripheral blood progenitor cells," Blood, vol. 103, no. 2, pp. 538-544, 2004.

[128] S. Appel, A. Rupf, M. M. Weck et al., "Effects of imatinib on monocyte-derived dendritic cells are mediated by inhibition of nuclear factor-kappaB and Akt signaling pathways," Clinical Cancer Research, vol. 11, no. 5, pp. 1928-1940, 2005.

[129] H. Wang, F. Cheng, A. Cuenca et al., "Imatinib mesylate (STI-571) enhances antigen-presenting cell function and overcomes tumor-induced CD4+ T-cell tolerance," Blood, vol. 105, no. 3, pp. 1135-1143, 2005. 
[130] C. Borg, M. Terme, J. Taïeb et al., "Novel mode of action of c-kit tyrosine kinase inhibitors leading to NK cell-dependent antitumor effects," Journal of Clinical Investigation, vol. 114, no. 3, pp. 379-388, 2004.

[131] J. Taieb, N. Chaput, C. Ménard et al., "A novel dendritic cell subset involved in tumor immunosurveillance," Nature Medicine, vol. 12, no. 2, pp. 214-219, 2006.

[132] G. W. Chan, G. Gorgun, K. B. Miller, and F. M. Foss, "Persistence of host dendritic cells after transplantation is associated with graft-versus-host disease," Biology of Blood and Marrow Transplantation, vol. 9, no. 3, pp. 170-176, 2003.

[133] M. Deininger, E. Buchdunger, and B. J. Druker, "The development of imatinib as a therapeutic agent for chronic myeloid leukemia," Blood, vol. 105, no. 7, pp. 2640-2653, 2005.

[134] C. Louvet, G. L. Szot, J. Lang et al., "Tyrosine kinase inhibitors reverse type 1 diabetes in nonobese diabetic mice," Proceedings of the National Academy of Sciences of the United States of America, vol. 105, no. 48, pp. 18895-18900, 2008.

[135] L. K. M. Shoda, D. L. Young, S. Ramanujan et al., "A comprehensive review of interventions in the NOD mouse and implications for translation," Immunity, vol. 23, no. 2, pp. 115-126, 2005.

[136] Y. Aono, Y. Nishioka, M. Inayama et al., "Imatinib as a novel antifibrotic agent in bleomycin-induced pulmonary fibrosis in mice," American Journal of Respiratory and Critical Care Medicine, vol. 171, no. 11, pp. 1279-1285, 2005.

[137] J. H. W. Distler, A. Jüngel, L. C. Huber et al., "Imatinib mesylate reduces production of extracellular matrix and prevents development of experimental dermal fibrosis," Arthritis and Rheumatism, vol. 56, no. 1, pp. 311-322, 2007.

[138] A. Akhmetshina, C. Dees, M. Pileckyte et al., "Dual inhibition of c-abl and PDGF receptor signaling by dasatinib and nilotinib for the treatment of dermal fibrosis," FASEB Journal, vol. 22, no. 7, pp. 2214-2222, 2008.

[139] A. V. Kamath, J. Wang, F. Y. Lee, and P. H. Marathe, "Preclinical pharmacokinetics and in vitro metabolism of dasatinib (BMS-354825): a potent oral multi-targeted kinase inhibitor against SRC and BCR-ABL," Cancer Chemotherapy and Pharmacology, vol. 61, pp. 365-376, 2008.

[140] P. Kaur, N. Feldhahn, B. Zhang et al., "Nilotinib treatment in mouse models of P190 Bcr/Abl lymphoblastic leukemia," Molecular Cancer, vol. 6, article 67, 2007.

[141] F. R. Luo, Z. Yang, A. Camuso et al., "Dasatinib (BMS-354825) pharmacokinetics and pharmacodynamic biomarkers in animal models predict optimal clinical exposure," Clinical Cancer Research, vol. 12, no. 23, pp. 7180-7186, 2006.

[142] C. E. Daniels, M. C. Wikes, M. Edens et al., "Imatinib mesylate inhibits the profibrogenic activity of TGF- $\beta$ and prevents bleomycin mediated lung fibrosis," Journal of Clinical Investigation, vol. 114, pp. 1308-1316, 2004.

[143] S. Wang, M. C. Wilkes, E. B. Leof, and R. Hirschberg, "Imatinib mesylate blocks a non-Smad TGF-beta pathway and reduces renal fibrogenesis in vivo," FASEB Journal, vol. 19, no. 1, pp. 1-11, 2005.

[144] H. Yoshiji, R. Noguchi, S. Kuriyama et al., "Imatinib mesylate (STI-571) attenuates liver fibrosis development in rats," AJP_Gastrointestinal and Liver Physiology, vol. 288, pp. G907-G913, 2005.

[145] C. Leipner, K. Grün, A. Müller et al., "Imatinib mesylate attenuates fibrosis in coxsackievirus b3-induced chronic myocarditis," Cardiovascular Research, vol. 79, no. 1, pp. 118-126, 2008.

[146] J. Gordon and R. Spiera, "Imatinib and the treatment of fibrosis: recent trials and tribulations," Current Rheumatology Reports, vol. 13, pp. 51-58, 2011.

[147] J. Kay and W. A. High, "Imatinib mesylate treatment of nephrogenic systemic fibrosis," Arthritis and Rheumatism, vol. 58, no. 8, pp. 2543-2548, 2008.

[148] R. F. Spiera, J. K. Gordon, J. N. Mersten et al., "Imatinib mesylate (gleevec) in the treatment of diffuse cutaneous systemic sclerosis: results of a 1-year, phase IIa, single-arm, open-label clinical trial," Annals of the Rheumatic Diseases, vol. 70, pp. 1003-1009, 2011.

[149] C. E. Daniels, J. A. Lasky, A. H. Limper, K. Mieras, E. Gabor, and D. R. Schroeder, "Imatinib treatment for idiopathic pulmonary fibrosis: randomized placebo-controlled trial results," American Journal of Respiratory and Critical Care Medicine, vol. 181, pp. 604-610, 2010.

[150] Y. Shi and J. Massagué, "Mechanisms of TGF-beta signaling from cell membrane to the nucleus," Cell, vol. 113, no. 6, pp. 685-700, 2003.

[151] M. Trojanowska, "Noncanonical transforming growth factor beta signaling in scleroderma fibrosis," Current Opinion in Rheumatology, vol. 21, no. 6, pp. 623-629, 2009. 
[152] N. Iwamoto, J. H. Distler, and O. Distler, “Tyrosine kinase inhibitors in the treatment of systemic sclerosis: from animal models to clinical trials," Current Rheumatology Reports, vol. 13, pp. 21-27, 2011.

[153] A. M. Pendergast, "The Abl family kinases: mechanisms of regulation and signaling," Advances in Cancer Research, vol. 85, pp. 51-100, 2002.

[154] S. Bhattacharyya, W. Ishida, M. Wu et al., "A non-Smad mechanism of fibroblast activation by transforming growth factor-beta via c-Abl and Egr-1: selective modulation by imatinib mesylate," Oncogene, vol. 28, no. 10, pp. 1285-1297, 2009.

[155] J. Pannu, Y. Asano, S. Nakerakanti et al., "Smad1 pathway is activated in systemic sclerosis fibroblasts and is targeted by imatinib mesylate," Arthritis and Rheumatism, vol. 58, no. 8, pp. 2528-2537, 2008.

[156] S. S. Nakerakanti, A. M. Bujor, and M. Trojanowska, "CCN2 is required for the TGF- $\beta$ induced activation of Smad1 - Erk1/2 signaling network," PLoS One, vol. 6, Article ID e21911, 2011.

[157] A. M. Bujor, Y. Asano, P. Haines, R. Lafyatis, and M. Trojanowska, "The c-Abl tyrosine kinase controls protein kinase C $\delta$-induced Fli-1 phosphorylation in human dermal fibroblasts," Arthritis \& Rheumatism, vol. 63, pp. 1729-1737, 2011.

[158] B. Maurer, J. Stanczyk, A. Jüngel et al., "MicroRNA-29, a key regulator of collagen expression in systemic sclerosis," Arthritis and Rheumatism, vol. 62, no. 6, pp. 1733-1743, 2010.

[159] M. Deininger, M. Schleuning, H. Greinix et al., "The effect of prior exposure to imatinib on transplant-related mortality," Haematologica, vol. 91, pp. 452-459, 2006.

[160] S. A. Giralt, M. Arora, J. M. Goldman et al., "Impact of imatinib therapy on the use of allogeneic haematopoietic progenitor cell transplantation for the treatment of chronic myeloid leukaemia," British Journal of Haematology, vol. 137, pp. 461-467, 2007.

[161] V. G. Oehler, T. Gooley, D. S. Snyder et al., "The effects of imatinib mesylate treatment before allogeneic transplantation for chronic myeloid leukemia," Blood, vol. 109, no. 4, pp. 1782-1789, 2007.

[162] N. S. Majhail, C. A. Schiffer, and D. J. Weisdorf, "Improvement of pulmonary function with imatinib mesylate in bronchiolitis obliterans following allogeneic hematopoietic cell transplantation," Biology of Blood and Marrow Transplantation, vol. 12, no. 7, pp. 789-791, 2006.

[163] L. Magro, B. Catteau, V. Coiteux, B. Bruno, J. P. Jouet, and I. Yakoub-Agha, "Efficacy of imatinib mesylate in the treatment of refractory sclerodermatous chronic GVHD," Bone Marrow Transplantation, vol. 42, no. 11, pp. 757-760, 2008.

[164] A. Olivieri, F. Locatelli, M. Zecca et al., "Imatinib for refractory chronic graft-versus-host disease with fibrotic features," Blood, vol. 114, no. 3, pp. 709-718, 2009.

[165] L. Magro, M. Mohty, B. Catteau et al., "Imatinib mesylate as salvage therapy for refractory sclerotic chronic graft-versus-host disease," Blood, vol. 114, no. 3, pp. 719-722, 2009.

[166] M. Stadler, R. Ahlborn, H. Kamal et al., "Limited efficacy of imatinib in severe pulmonary chronic graft-versushost disease," Blood, vol. 114, pp. 3718-3720, 2009.

[167] G. Rosti, F. Palandri, F. Castagnetti et al., "Nilotinib for the frontline treatment of $\mathrm{Ph}(+)$ chronic myeloid leukemia," Blood, vol. 114, pp. 4933-4338, 2009.

[168] C. J. Fraser and K. S. Baker, "The management and outcome of chronic graft-versus-host disease," British Journal of Haematology, vol. 138, no. 2, pp. 131-145, 2007.

\section{This article should be cited as follows:}

Jacopo Olivieri, Sabrina Coluzzi, Imma Attolico, and Attilio Olivieri, “Tirosin Kinase Inhibitors in Chronic Graft versus Host Disease: From Bench to Bedside,” TheScientificWorldJOURNAL, vol. 11, pp. 1908-1931, 2011. 


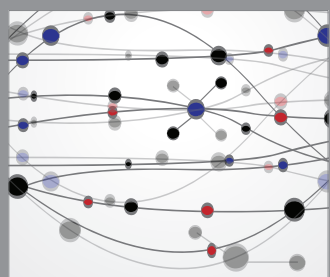

The Scientific World Journal
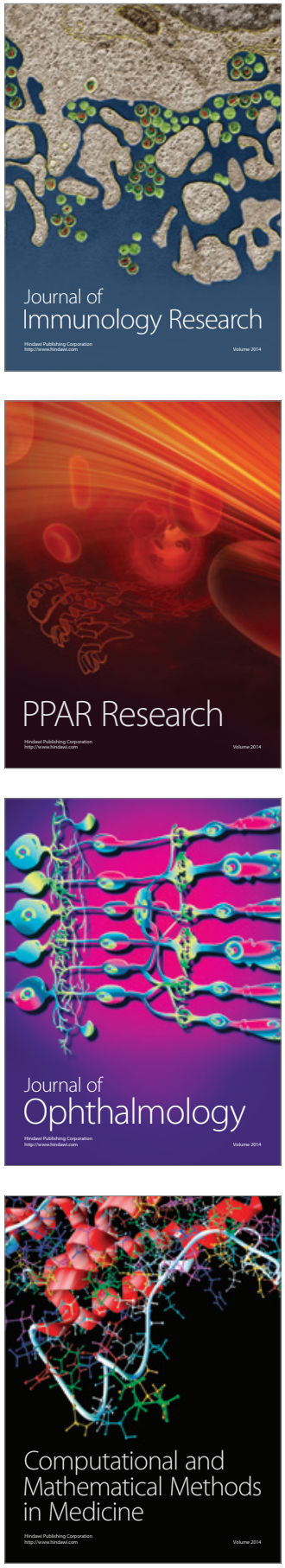

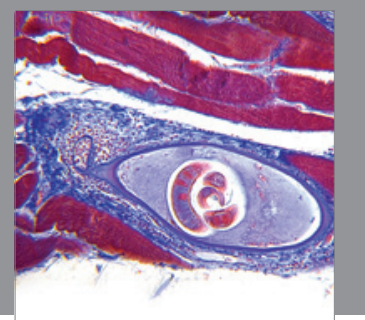

Gastroenterology

Research and Practice


\section{Hindawi}

Submit your manuscripts at

http://www.hindawi.com
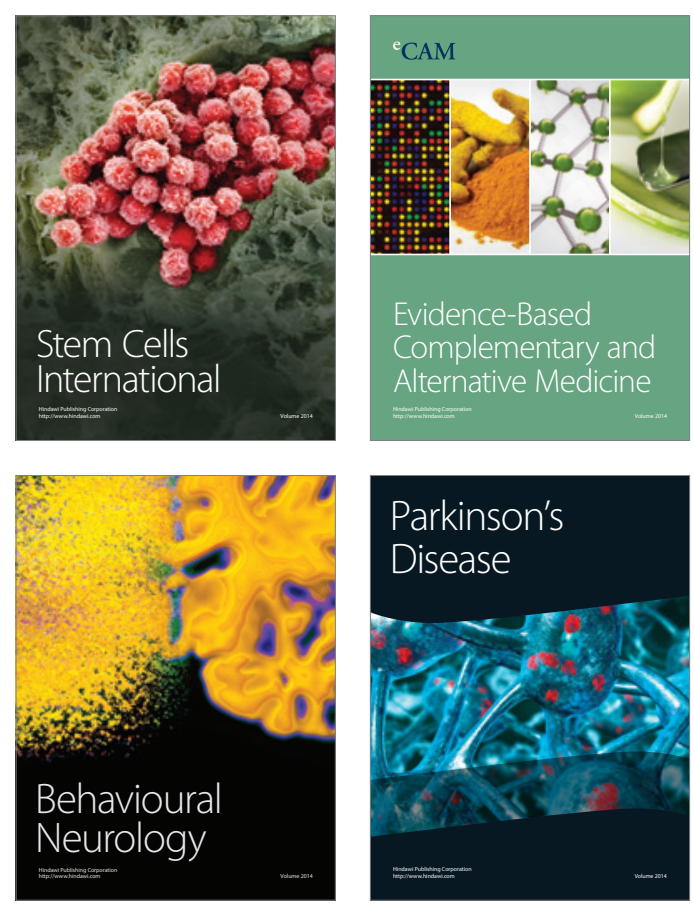



Journal of
Diabetes Research

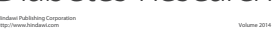



Disease Markers
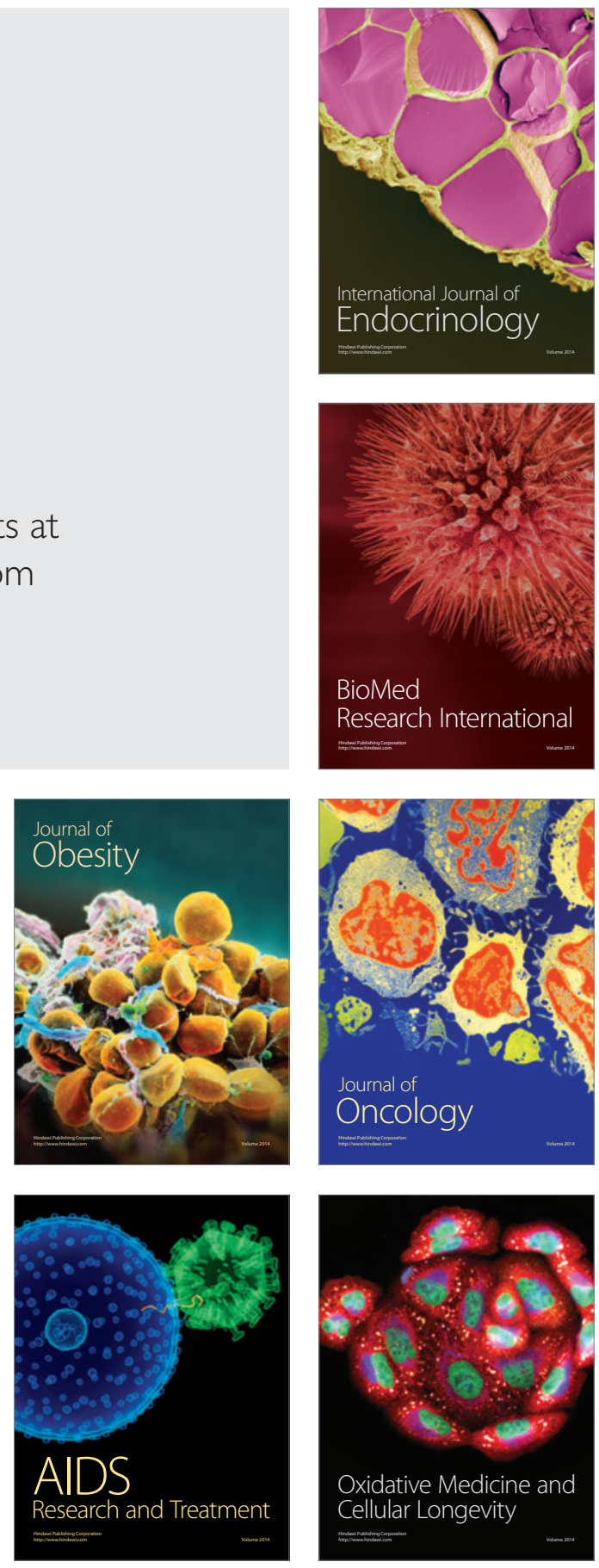